\title{
Italo Calvino oder vom Lesen und Lieben auf den Bäumen
}

Innerhalb unserer einführenden Beschäftigung mit den Leseformen, Liebesformen, Leserfiguren und Liebesfiguren in den Romanischen Literaturen der Welt möchte ich gerne ein zweites und letztes Mal - und ich hoffe, Sie sehen mir dies nach - auf einen Text Italo Calvinos zurückkommen, einen Text, der uns überdies einen unmittelbaren sinnlichen Zugang zum 18. Jahrhundert ermöglichen wird. Kaum ein anderer europäischer Schriftsteller hat wie Italo Calvino derart intensiv und zugleich spielerisch über die Möglichkeiten nachgedacht, die der Akt des Lesens in Verbindung mit dem Akt des Liebens für die Literaturen in der Moderne bereithält. So verwundert es auch nicht, wenn Calvino immer wieder unterschiedlichste Leserfiguren in seine Romane einbaute, an welche sich komplexe Liebesgeschichten anknüpften. Dies war eines der großen Themen des Calvino’schen Schreibens, vielleicht sogar sein größtes Thema überhaupt.

Italo Calvino war ein literarischer Meister, ebenso auf dem Gebiet der experimentellen Erzählkunst wie auch seiner stets damit verbundenen ästhetischen Reflexionen über die Literatur und ihr Verhältnis zur dargestellten Wirklichkeit. Immer wieder kreisten seine Überlegungen um die Unendlichkeit der literarischen Möglichkeiten und über deren rational begrenzbare Notwendigkeiten der Ausschöpfung. Es ist gerade diese am Rationalen orientierte Neugierde an den nicht nur ästhetischen und philosophischen, sondern gerade auch an den logischen Möglichkeiten des Schreibens, die ihn recht früh mit dem Werk des Argentiniers Jorge Luis Borges in eine fruchtbare Beziehung brachte. Hinzu kamen die Schreibstrategien und Auflagen des Ouvroir de littérature potentielle rund um Raymond Queneau und Georges Perec, die ihn immer wieder von neuem stimulierten.

Im Folgenden soll es in der gebotenen Kürze um einen der - sicherlich nicht nur für mich - schönsten Texte dieses italienischen Autors gehen, dem Roman Il barone rampante, der in den Jahren 1956 und 1957 entstand. Es sind die Jahre, in welchen gleichsam der Takeoff für die Literaturen im Zeichen der Postmoderne entstand, wenn wir von den frühen Ficciones des Jorge Luis Borges einmal absehen. Aus meiner Sicht dabei unzweifelhaft ist, dass die Literaturen der Welt eine Reihe von Themenstellungen entwickelten, welche im Bereich der Philosophie erst mit einer gewissen Verspätung aufgegriffen, zumindest teilweise aber auch verzögert „ausgedacht“ werden sollten. Denn die Literaturen der Welt bilden nicht nur eine Experimentierfläche für das Heraufziehende und noch Ungedachte, sondern stellen auch eine Art Seismograph für alle kommenden Entwicklungen dar, die von Belang und Bedeutung für die Geschichte der 
Menschheit sind. Doch bemühen wir vorerst diese seismographische Funktion der Literatur nicht weiter.

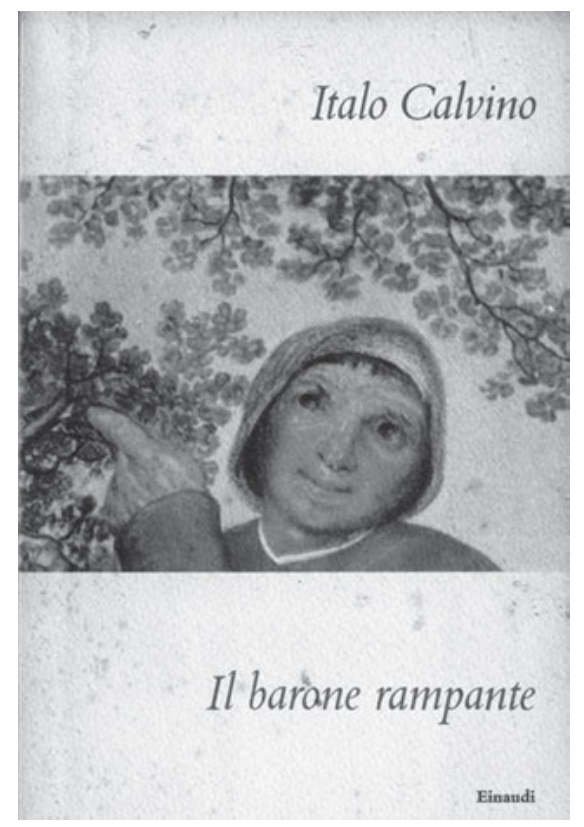

Abb. 34: Cover der Erstausgabe von Italo Calvinos Il Barone rampante.

Worum geht es in diesem insgesamt in dreißig durchlaufend nummerierte Kapitel eingeteilten Roman? Wir könnten darauf antworten, dass es sich auf den ersten Blick um einen Text handelt, der ein wenig der Geschichte unseres „Suppenkasper“ verwandt ist. Denn im ersten Kapitel, das im Text gleich im ersten Satz auf den Sommer des Jahres 1767 datiert ist, wird aus der Perspektive des Bruders der Hauptfigur Cosimo ein Geschehen geschildert, das sich so oder so ähnlich an vielen Mittagstischen nicht nur Italiens abgespielt haben dürfte. Cosimo Piovasco di Rondò, der älteste Sohn des Barons von Rondò und dessen deutscher Frau, der Tochter des Generals von Kurtewitz, weigert sich nachhaltig, eine Schneckensuppe zu essen, der als Hauptgericht dann auch noch ein Schneckenmahl folgen soll. Soweit so alltäglich. Doch die Schnecken haben es in sich.

Denn die Zusammenstellung des Mittagsmahles geht auf Cosimos Schwester Battista zurück, die ihr grausames Spiel mit allerlei Tieren in ihrer Umgebung treibt. Ihr von der Familie geduldetes Hobby besteht darin, nicht nur Schnecken zu fangen und zu köpfen, sondern auch viele andere Tiere wie Regenwürmer, Mäuse, Vögel usw. zu malträtieren und in der Folge in verschiedensten Formen 
dargereicht als gastronomische Spezialitäten anzubieten. Sie kocht sozusagen ihr eigenes Süppchen, das freilich andere dann auslöffeln müssen. Und Cosimo hat den Hals gestrichen voll.

\section{Il berove nouppante}

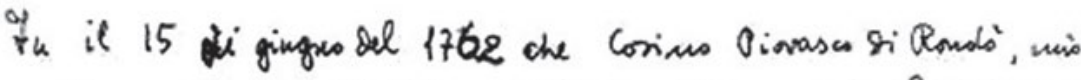
frablets, sdetle per l'ultima weta in werzs a uri. Biciondo come forse orgi. Evanums velle rala de paurs sella ustra villa g'Cuntoo. sh, le finesthe pases inquadranus i folti nam

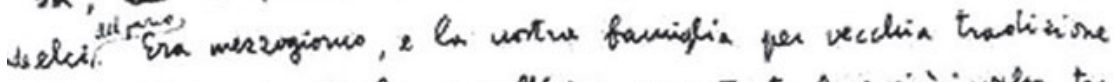

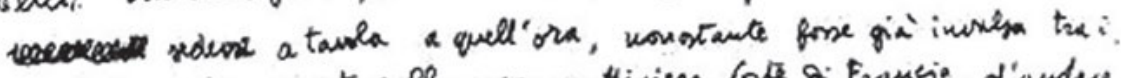

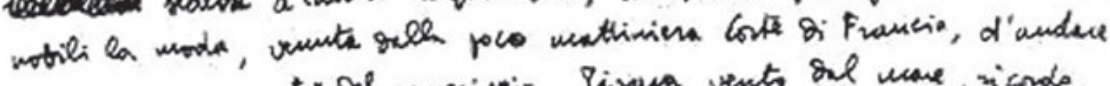

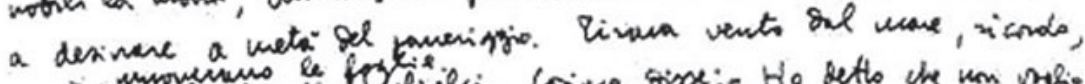

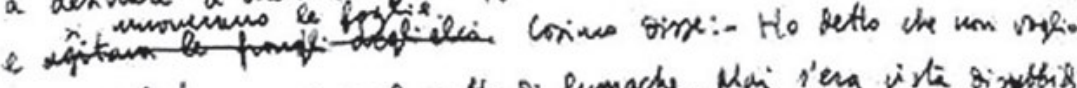

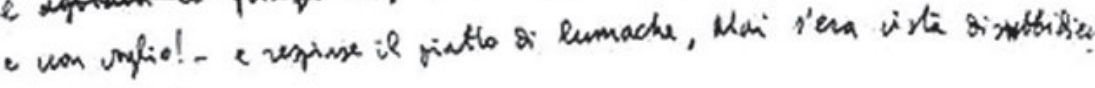

In pir prove.

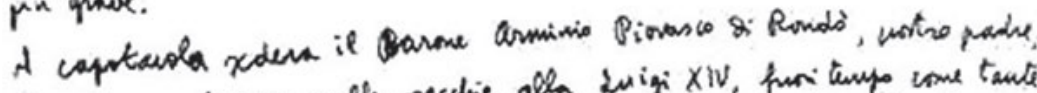

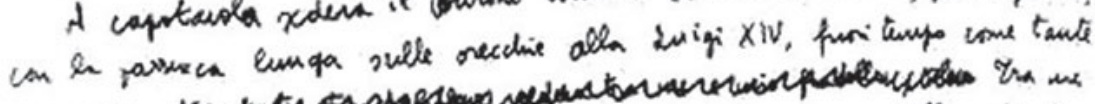

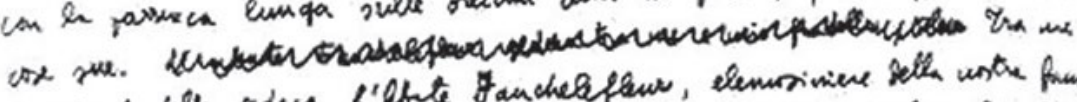

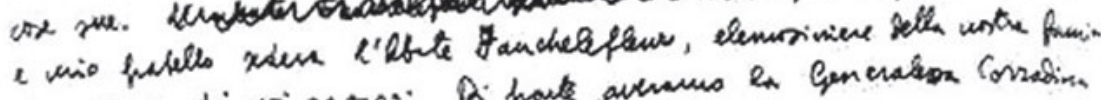

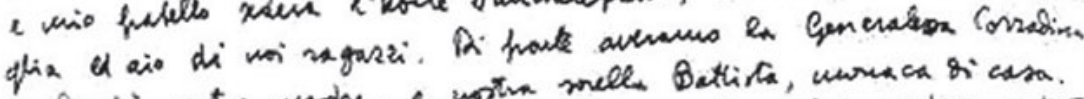

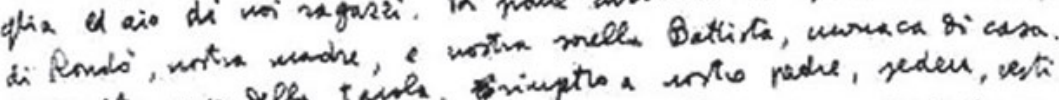

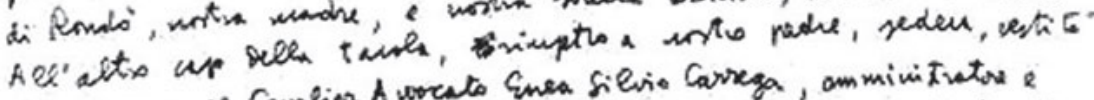

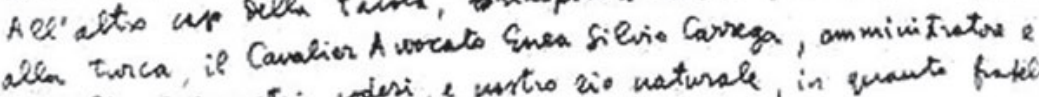

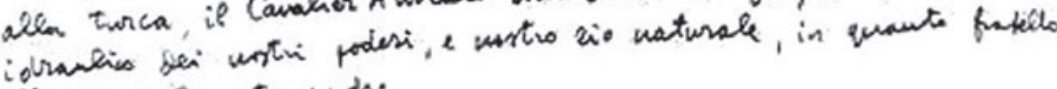

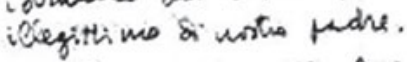

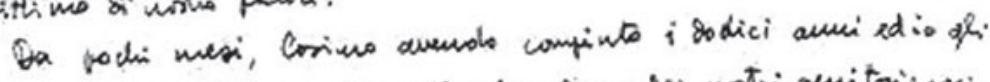

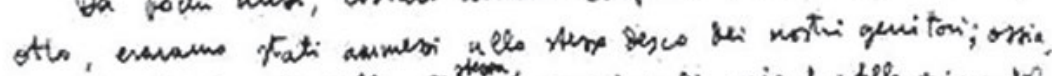

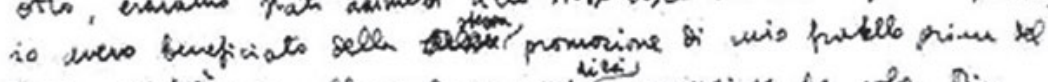

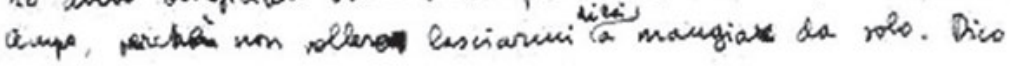

Abb. 35: Handschriftliches Incipit des Barone rampante. 
Eines schönen Tages hatten Cosimo und sein jüngerer Bruder Biagio, wie gesagt die Erzählerfigur dieses Romans, das Schneckenfass entdeckt, in dem die von Battista gefangenen Schnecken in einer Art Schneckenhölle (wie es im Text heißt) gefangen gehalten wurden. Ein Loch in dieses Fass zu bohren und die Schnecken in die verdiente Freiheit zu führen war ein Weniges für die beiden Buben, den achtjährigen Biagio und vor allem den Rädelsführer, den zwölfjährigen Cosimo. Dieses tierfreundliche Tun, welches heute mit einem Tierwohllabel ausgezeichnet werden würde, ward aber noch in der Nacht von Schwester Battista entdeckt und vom Vater durch Prügelstrafe und Verurteilung zu Karzer bei Wasser und Brot hart bestraft worden. Und nun kamen die Schnecken auch noch auf den Tisch.

Cosimos Wiedereingliederung in die Runde des mittäglichen Familientisches wurde als erschwerende Präambel daher das Kosten und Verspeisen eines von der sadistisch gelagerten Schwester Battista gekochten Schneckensüppchens vorgeschaltet. Genau hieran entzündet sich die Rebellion des jungen Baron Cosimo. Er weigert sich nicht nur, sondern greift dem Ausruf des Herrn Vater - „Weg von diesem Tische!“ - voraus, indem er aus eigenem Antrieb die Runde verlässt und auf einen nahegelegenen Baum klettert, eine im von Calvino geliebten Ligurien häufige Steineiche (elce oder quercus ilex für die Botaniker unter Ihnen) mit dem Versprechen, nie mehr von den Bäumen herunterzukommen. Und er wird dieses dem Vater gegebene Wort auch einhalten, wird also zeit seines Lebens den Boden, die Erde seines Heimatlandes, nicht mehr betreten, sondern einige Meter höher auf den Bäumen leben. Der junge Baron hat Charakter.

Die narrative Ausgangssituation dieses Romans ist damit klar: Es ist eine Art Gegen-Welt, vielleicht auch eine Welt auf dem Kopf, die sich Cosimo fortan konstruiert und die in immer stärkerer Weise nicht nur literarisch ausgestaltet, sondern auch als Gegenwelt gegen die offizielle Welt seiner Zeit gestaltet wird. Denn in gewisser Weise handelt es sich um einen historischen Roman, auch wenn die Story von Italo Calvino frei erfunden ist. Die historischen Ingredienzien dieses Romans sind es nicht.

Dies beginnt schon bei den dominanten Themen der Geschichte. Insbesondere das Thema der Freiheit, zugleich natürlich auch eines der zentralen Themen des 18. Jahrhunderts, ist dabei seit der Befreiung der wehrlosen Schnecken aus ihrer Schneckenhölle zum Leitthema auserkoren und bestimmt den weiteren Lebensweg Cosimos nicht weniger als das der individuellen und kollektiven Selbstverwirklichung. Die Liebe kommt ein wenig später hinzu, haben Sie noch Geduld! Dass die Gegenwelt als eine konkret realisierte Utopie in so unmittelbarer Nähe der offiziellen, der ,eigentlichen“ Welt angesiedelt ist, zeigt, dass hier nicht nur eine abstrakte Utopie an einen Ort, den es nicht gibt - U-topos: kein Ort, nirgends - verlagert wird, sondern in die gesellschaftliche Realität zumindest 
unseres Textes, aber sicherlich auch des 18. Jahrhunderts insgesamt direkt eingebettet wird.

Noch ein Wort zur Gattung, die wir natürlich nicht der des historischen Romans zuordnen können: Dazu fehlt es an der Realität nachgebildetem historischen Personal. Doch von Beginn an sei betont, dass das 18. Jahrhundert als Diegese des Romans natürlich die parabelhafte Dimension nicht ausschließen kann, ja sie vielleicht sogar noch verstärkt, insoweit Ereignisse des Romans wie etwa militärische Auseinandersetzungen, Partisanenkämpfe usw. mit Ereignissen und autobiographischen Erfahrungen im Italien des 20. Jahrhunderts und im Italien Italo Calvinos durchaus präsent und eingeflochten sind. Wir haben es folglich mit einem historisch hochkomplexen, auf zumindest zwei verschiedenen Ebenen spielenden Roman zu tun.

Wenn ich gerade von einem Roman gesprochen habe, so muss ich gleich hinzufügen, dass die Gattungsform - keineswegs erstaunlich bei einem poeta doctus wie Italo Calvino - auch in direkter Beziehung zur Romandiegese steht. Daher können wir parallel zur offenen und schwankenden Begrifflichkeit des 18. Jahrhunderts diesen Text durchaus als „roman“ im Sinne des 18. Jahrhunderts begreifen und dürfen ihn in einer Linie sehen mit eben jenen Romanen und contes philosophiques, die auch noch für die Leser des zu Ende gehenden 20. und des beginnenden 21. Jahrhunderts ganz wesentlich den Charme des 18. Jahrhunderts mitgeprägt haben und weiterhin prägen. Gerade die contes philosophiques, meisterhaft von einem Voltaire ausgeführt, verkörpern wie kaum eine andere literarische Form die spielerische Leichtigkeit einer vieldeutigen Literatur, gepaart mit einem schneidenden Verstand, der gleichzeitig auf gesellschaftliche Kritik und Veränderung drängt. Aus der Distanz des 20. Jahrhunderts bediente sich Italo Calvino meisterhaft dieser Form.

In Il barone rampante haben wir es also zugleich auch mit einer philosophischen Erzählung im Stile eines Voltaire zu tun, in der es oft orientalisierende und märchenhafte Züge, aber auch eine Vielzahl didaktischer Grundmuster gab. Auf die Verbindung zwischen Romandiegese, Gattungswahl und Beziehungen zu anderen Künsten komme ich aber noch zurück.

Wir können aber schon hier mit Ulrich Schulz-Buschhaus ${ }^{1}$ sagen, dass es sich um einen Text über das 18. Jahrhundert im Stile des 18. Jahrhunderts handelt, der an Eichendorffs Motiv vom Taugenichts auf den Bäumen anknüpfend eine Vielzahl architextueller Relationen herstellt zum Bildungsroman, zum Erziehungsroman

1 Vgl. Schulz-Buschhaus, Ulrich: Calvinos politischer Roman vom Baron auf den Bäumen. In: Romanische Forschungen (Frankfurt am Main) 90 (1978), S. 17-34. 
und nicht zuletzt auch zum damals entstehenden historischen Roman. Mit all diesen Beziehungen pflegt der italienische Romancier aber einen so ludischen Umgang, dass der Eindruck jener Leichtigkeit entsteht, welche durchaus in das Umfeld der Literaturen im Zeichen der Postmoderne gehört und die Lust an der Lektüre steigert.

Was aber macht ein junger Mann aus adligem Hause, der künftige Baron von Rondò, auf den Bäumen, will er denn sein Wort halten, niemals wieder herunterzusteigen, um erneut als ein „normaler“ Mensch an den „normalen“ Grausamkeiten dieses Lebens teilzunehmen? Er muss natürlich versuchen, sich zunächst einmal eine eigene Welt aufzubauen. Und wir schauen ihm dabei zu. Er tut dies zunächst auf der Ebene des Raumes, indem er versucht, sich einige Meter über dem Erdboden ein eigenes Reich zu erschaffen: mit einer eigenen Topographie, mit eigenen Lieblingsorten und einer eigenen Infrastruktur, die ihm nicht nur einen neuen Blick auf die Welt gleichsam aus einer ruhenden Vogelperspektive erlaubt, sondern auch existierende Grenzziehungen auf der Erde ganz einfach missachtet: eine räumliche Gegen-Welt.

Cosimo begibt sich sogleich - und zwar schon im zweiten Kapitel des Romans in den durch eine Mauer vom eigenen Grundstück der Rondò abgetrennten Nachbargarten, der eine Vielzahl für den künftigen Baron bislang unbekannter und die Sinnenwelt reizender Gegenstände enthält. Er findet sich unversehens in einem Zaubergarten wieder, ist doch jener der Familie der Ondariva ganz typisch für die Gärten des 18. Jahrhunderts von einer Vegetation geprägt, welche durch die unterschiedlichsten Forschungsreisen und botanischen Expeditionen des 18. Jahrhunderts nach Europa geholt worden war. Wie in einem Fraktal vereint, findet sich hier die ganze Vegetation unseres Planeten wieder, nicht nur die Steineichen. Denken Sie dabei an den vor den Toren der Universität Potsdam liegenden Park von Sanssouci mit all seinen Bäumen und Sträuchern aus allen Weltteilen, und darin vielleicht auch an den Paradiesgarten, der gar nicht weit von hier entfernt liegt.

In den letzten Kapiteln des Bandes wird uns übrigens das Ende dieses Prozesses vor Augen geführt, in Gestalt einer Transformation der Vegetation, die einer enormen Reduktion der Unterschiede in den Landschaftsformen gleichkommt. Die gesamte Physiognomie dieser mediterranen Landschaft wird verändert, und zwar nicht allein in den umfriedeten Grundstücken, sondern im gesamten Küstenbereich: Eine gewaltige Verarmung tritt ein, die freilich längst historisch geworden ist und uns heutigen Besuchern der Mittelmeerlandschaften gar nicht mehr auffällt. So werden die Küsten Liguriens, die einstmals von der Pinie und der Steineiche geprägt waren, nunmehr von den Bäumen Australiens, Asiens und Arabiens beherrscht. Die Pinie hat sich auf die höheren Lagen - wenn überhaupt noch - zurückgezogen und hat dem Eukalyptus, aber vor allem der Palme, 
jenem - wie es im Text heißt - traurigen Baum der Wüsten, Platz gemacht. Diese massiven Eingriffe des Menschen in die Vegetation sind für unseren Baron auf den Bäumen selbstverständlich von vitaler Bedeutung.

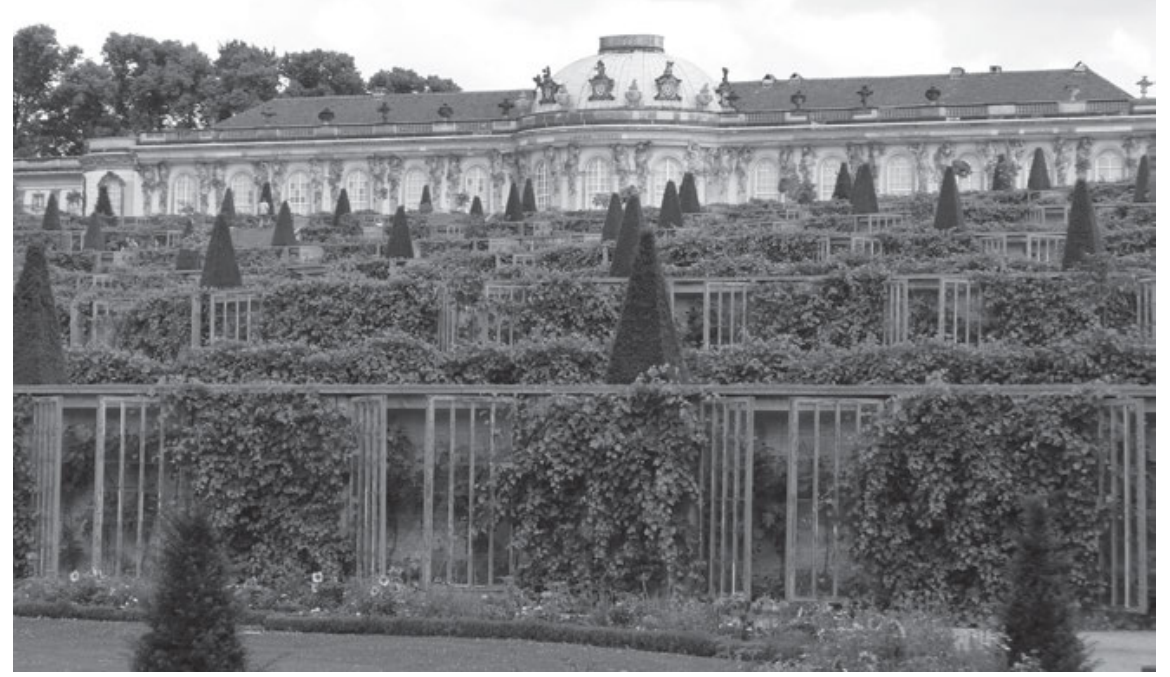

Abb. 36: Schloss Sanssouci in Potsdam am Hang des Weinberges (1745-1747).

Im Garten der Ondariva ist freilich die Vegetation nicht das einzige, das das Herz des künftigen Baron höher schlagen lässt. Denn bald schon sieht er mit erstaunten Augen, wie ein hübsches junges Mädchen in für ihr Alter zu großen Kleidern auf einer Schaukel sitzend gleichsam durch die Bäume gleitet und damit eine Art Zwischenstellung zwischen Himmel und Erde einnimmt. Da es sich um eine Begegnung handelt, die für beide letztlich von lebenslanger Bedeutung sein wird, wollen wir sie etwas näher betrachten und die Abenteuer der Liebe sich entwickeln sehen:

Es war ein blondes Mädchen, mit einer hochgesteckten, für ein Kind ein wenig komisch wirkenden Frisur, mit einem ebenfalls zu großen blauen Kleid, und der beim Schaukeln hochgeraffte Unterrock war überreich mit Spitzen besetzt. Die Kleine hatte die Augen leicht geschlossen und hielt die Nase in die Luft, als sei sie gewohnt, die große Dame zu spielen; sie biss in einen Apfel und neigte bei jedem Biss den Kopf der Hand entgegen, die den Apfel umklammern und sich zugleich am Seil der Schaukel festhalten musste; jedes Mal, wenn die Schaukel den Tiefpunkt ihrer Bahn erreichte, stieß sie sich ab, wobei sich die Spitzen ihrer Schühchen ins Erdreich bohrten, und blies sich die Schalenreste der verzehrten Apfelstücke von den Lippen; und dabei sang sie: „Oh là là là! La ba-la-nçoire ... “, wie ein kleines Mädchen 
singt, das sich aus Schaukel und Lied und Apfel schon nichts mehr macht (wenn ihm auch der Apfel noch etwas wichtiger ist) und das bereits andere Gedanken im Kopf hat. [...]

Viola sprang von ihrer Schaukel und begann Cosimos Schaukel sachte anzustoßen. „UH!“ Auf einmal hatte sie den Sitz der Schaukel, auf dem mein Bruder stand, gepackt und umgedreht. Es war ein Glück, dass Cosimo sich unausgesetzt an den Seilen festhielt! Sonst wäre er auf die Erde gepurzelt wie eine Salami.

„Verräterin!“, schrie er, und kletterte nach oben, wobei er sich an beide Taue klammerte, aber der Aufstieg war weit schwieriger als der Abstieg, vor allem da das blonde Mädchen einen seiner boshaftesten Augenblicke hatte und von unten an den Stricken in alle Himmelsrichtungen zog.

Schließlich erreichte er den dicken Ast und setzte sich rittlings darauf. Mit seinem Spitzenkragen trocknete er sich den Schweiß von der Stirn. „Haha, du hast es nicht geschafft!“ „Um ein Haar!“2

Das war also gerade noch einmal gut gegangen! Das hübsche blonde Mädchen hat ihren eigenen Kopf und steckt voller Überraschungen. Die erste Begegnung zwischen dem gerade erst auf die Bäume gekletterten Cosimo und der jungen Viola verläuft daher durchaus stürmisch. Noch ist es zu früh für eine Liebesgeschichte, aber wir sehen schon, wie sich in Cosimo etwas für das junge, attraktive Mädchen zu regen beginnt.

Auffällig ist, dass sich Viola in ständiger Bewegung befindet und zwischen Himmel und Erde gleichsam zu schweben scheint, während sich der gerade noch rechtzeitig gerettete Cosimo wieder sicher und fest in die Wipfel der Bäume zurückgezogen hat und auf seine Verräterin und Verführerin blickt. Das Mädchen aber beißt in einen Apfel, ist also als neue Eva die Versuchung in Person. Der Apfel fällt ihr aus der Hand, als sie den Eindringling Cosimo erblickt, der sich in ihren Garten gestohlen hat. Schnell jedoch fängt sie sich wieder und beherrscht die Situation. Ihren Apfel hebt Cosimo auf und verspeist ihn: Diese Einverleibung ist ein deutliches Zeichen dafür, dass er fortan von ihren Reizen, von ihrer Verführungskraft eingenommen und keineswegs nur vorübergehend von ihrer Sinnlichkeit betört ist. Das Verspeisen von Violas Äpfelchen ist wie ein Liebesbund zwischen den beiden eigensinnigen Adeligen.

Bereits in dieser ersten Begegnung wird deutlich, dass Viola die in der Lebenswelt weitaus erfahrenere ist. Sie lässt sich keinen Bären aufbinden und glaubt Cosimo nicht, als dieser sich zunächst als Obstdieb, danach als gefährlicher Brigant vorstellt. Denn das junge Mädchen weiß es besser: Sie kennt sowohl die kleinen Obstdiebe als auch die im Wald lebenden Briganten - und allen voran Gian dei Brughi - persönlich, kann Cosimo also schnell der Lüge überführen.

2 Calvino, Italo: Il barone rampante. Prefazione e note di Tonio Cavilla. Turin: Einaudi 1965, S. $37 \mathrm{ff}$. 
Cosimo hat bei weitem nicht die Lebenstüchtigkeit und Gewandtheit, die Viola auszeichnen. Immerhin ist er für sie ein schräger Vogel auf den Bäumen und mit seinem gutmütigen Charakter der Schnelligkeit und dem Wankelmut der jungen Adligen unterlegen, wäre da nicht seine Standfestigkeit und Standhaftigkeit, die freilich auf eine arge Probe gestellt werden. Es ist die erste Bewährung des jungen Baron, die glücklich zu seinen Gunsten ausfällt.

Während Cosimo nur dem einen Element der Luft - beziehungsweise den Wipfeln der Bäume - zugehört, herrscht die schöne Viola über den gesamten Raum zwischen Himmel und Erde. Sie ist Gebieterin auf dem Boden; aber auch in der Höhe, auf den Bäumen, kann sie versuchen, dem jungen Baron nahezukommen - in des Wortes vielfacher Bedeutung. Sie kann auf der Erde leben, kann sich dort bewegen wo und wie sie will, während Cosimo an den Bereich der Bäume und Baumwipfel gebunden bleibt. Sie kann aber auch - wie sich später zeigen wird - auf den Bäumen leben und nicht nur das: Sie vermag dort zu lieben, in jener heftigen Art, die ihr gesamtes pendelndes Wesen auszeichnet. La donna è mobile, könnten wir hier aus Rigoletto vieldeutig hinzufügen.

Wir haben es folglich mit zwei unterschiedlichen Charakteren zu tun, die einander bekämpfen, weil sie sich so unendlich lieben; zwei Königskinder, die zunächst zueinander nicht kommen können, nicht weil das Wasser viel zu tief, sondern weil der Graben zwischen ihren Welten (noch) zu groß ist. Violas spontaner Versuch, Cosimo zu ihrem Gefangenen zu machen, indem sie ihn auf die Schaukel lockt, um ihn dann von dieser herunterzuschütteln, scheitert; doch um ein Haar wäre ihr diese Tat gelungen. Aus Cosimos Geschichte wäre keine geworden, wäre er wie eine Salami heruntergepurzelt auf den Boden. Er wäre ein selbsternannter Herr der Lüfte geblieben, der gleich nach wenigen Stunden schon wieder auf den Boden der Tatsachen zurückgeholt worden wäre. So aber setzt sich sein Leben auf den Bäumen fort und der junge Mann erschafft Stück für Stück seine eigene Welt.

Fortan hat Cosimo nicht nur einen negativen Grund - die Rebellion gegen eine ihm verhasste, überkommene Ordnung -, sondern auch einen positiven Anreiz, auf den Bäumen zu bleiben: Seine ihm zunächst noch unbewusste Liebe zur jungen, schönen Viola, die ihn freilich von Beginn an in sentimentale Abgründe stürzt und die stets den aktiven Part in ihrer Beziehung spielen wird. Doch Liebe auf den ersten Blick fragt nicht nach Abgründen. Der Ich-Erzähler des Romans hat schnell erkannt, dass sein Bruder in Viola einen vielleicht noch viel wichtigeren Grund gefunden hat, um seine Lebenskonzeption $\mathrm{zu}$ bewahren und sich selbst die eigene Standfestigkeit zu beweisen: die noch unbewusste, aber darum nicht weniger starke Liebe zum anderen Geschlecht, das in jeder Hinsicht $\mathrm{zu}$ ihm in einer Alteritätsbeziehung steht. In dieser Liebeskonstruktion Calvinos sind es die Gegensätze, die sich anziehen. Doch sie müssen auch gemeinsame Berührungspunkte besitzen, sonst wird aus der Liebe nichts. 
Viola ist für Cosimo die Andere schlechthin. Aber prekär wird der Bereich, in dem sich die beiden künftigen Liebenden treffen können, von Beginn an stets bleiben. Nur auf der Schaukel, zwischen Himmel und Erde, scheint es einen eigenen Raum unsteter Verbindung zu geben: Nur die Schaukel vermag in ihrer Pendelbewegung, die Gegensätze kurzzeitig zu überbrücken. Sehen wir uns also dieses Instrument der Liebe in seiner Hin- und Her-Bewegung etwas näher an!

Auch wenn es sich bei den Protagonisten noch um Kinder handelt: Die erotische Dimension ihrer Beziehung steht außer Frage und macht sich an der Schaukel fest. Wir sind im Jahre 1767, und just aus jenem Jahr stammt eines der sicherlich berühmtesten und meistkopierten Gemälde des 18. Jahrhunderts überhaupt: eben „Die Schaukel“ des durch seine Italienreisen stark von italienischen Schöpfern angeregten französischen Malers Jean-Honoré Fragonard (1732 bis 1806), das hier in einer verkleinerten Abbildung vorliegt. Es zeigt uns die andere, die lebenslustige, luftige, liebeshungrige und auch erotische Seite des 18. Jahrhunderts, das ja keineswegs auf die Problematik abendländischer Rationalität und philosophischer Aufklärung reduziert werden kann. Italo Calvino zeichnet in seinem Roman ein wesentlich vielstimmigeres Bild jenes Jahrhunderts, das gleichwohl auf einen Aufstand gegen alles Alte, auf jene politische Revolution hinauslief, die nicht nur für Frankreich maßgebend war.

Jean-Honoré Fragonard steht in diesem 18. Jahrhundert als Maler, und sein vielleicht berühmtestes Gemälde „La balançoire“ als Ikone für eine Welt der Sinnlichkeit, die uns zugleich auch Einblick gibt in die Produktionstechnik der literarischen Palette Italo Calvinos. Denn selbstverständlich hat letzterer sehr bewusst und kunstvoll auf dieses berühmte Gemälde zurückgegriffen und lässt seine kleine Heldin den Hinweis auf die französische Herkunft ihres Tuns selbst geben, indem er sie ein französisches Lied singen lässt. Ein untrügliches Zeichen für die Leserschaft!

Calvino veränderte freilich einige Elemente, indem er etwa den seit dem Paradies semantisch aufgeladenen und in der Genesis mit dem Baum des Wissens in Verbindung stehenden Apfel hinzufügt, die Figur des älteren, das junge Mädchen am Zügel haltenden Mannes rechts unten fortlässt und - ein wenig deserotisierend - die Figur des männlichen Betrachters, ja des jungen Voyeurs, nach oben, und so aus der Blicklinie der Strumpfbänder, verbannt. Zugleich hat er aus den Jugendlichen Kinder gemacht und sie damit auch bezüglich ihres Lebensalters zunächst etwas von einer überbordenden Geschlechtlichkeit entfernt.

Gleichwohl sind auch bei Italo Calvino das Element des Schühchens und des Füßchens - beides sehr wichtige Sexualsymbole, wie wir der Traumdeutung von Sigmund Freud entnehmen dürfen - nicht aus der literarischen Textmalerei verschwunden. Calvino hat hier deutlich bild-textliche Techniken der Ekphrasis angewandt und damit versucht, seine Romandiegese nicht nur gattungsspezifisch und inhaltlich, sondern auch durch intermediale Einbindung als Dialog 
mit der Malerei mit der Leserschaft unserer Tage zu verbinden. Der italienische Romancier ist zu einem Bilderleser geworden, eine Variante, auf die wir noch des Öfteren bei ihm stoßen werden.

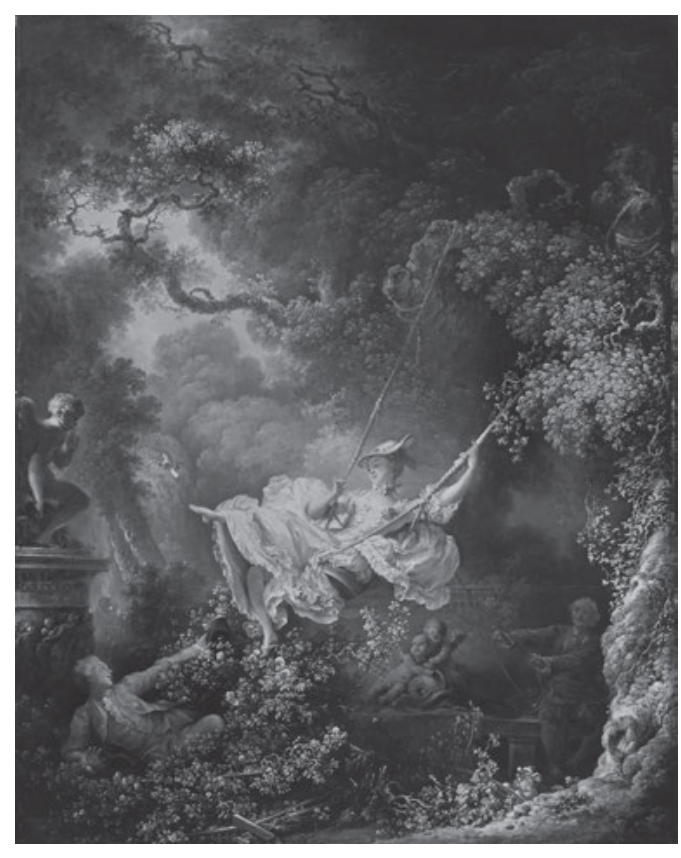

Abb. 37: „Die Schaukel“, Öl auf Leinwand von Jean-Honoré Fragonard, 1767-1768.

Damit sind Lust und Liebe - wie der weitere Verlauf des Romans zeigen wird jedoch nicht verbannt, so dass die Schaukel als erotisches Motiv weiterbestehen kann, wird sie doch später nach der Rückkehr Violas in die Villa und ihren Garten von der mittlerweile in Liebesdingen erfahrenen jungen Frau wieder an derselben Stelle aufgehängt. Es ist ein Anknüpfen an die Macht von Eros inmitten einer üppigen Vegetation, in der es überall blüht und sprießt. Nicht umsonst hat das erotische Motiv der Schaukel auch die Zeitgenossen Fragonards in Anschluss an seine Behandlung des Themas in Atem gehalten. Ein gutes Beispiel hierfür ist der berühmte Stich eines der großen Meister des 18. Jahrhunderts, Nicolas de Launay, der seinem Werk den Titel „Les hasards heureux de l'escarpolette“ gab. Lust und Leichtigkeit sind in diesen Bildern wie auch im Erzähltext Italo Calvinos, der in seiner kreativen Auseinandersetzung mit der Kunst des Jahrhunderts der Aufklärung zu einem aufmerksamen Bilder-Leser wird, überall zu spüren.

Wir haben aus den bisherigen Überlegungen und Untersuchungen bereits den Schluss ziehen dürfen, dass es sich bei Italo Calvino um einen Autor handelt, der überaus bewusst und geradezu konstruktivistisch die unterschiedlichsten 
Elemente präzise auf die Romandiegese, also auf die raumzeitlichen Koordinaten des von ihm Erzählten, zu beziehen versteht. Er ist ein raffinierter Künstler beim Spiel der Reflexe zwischen Text und Kontext und zugleich ein gelehrter Leser ebenso der textuellen wie der ikonischen Intertexte in Il barone rampante.

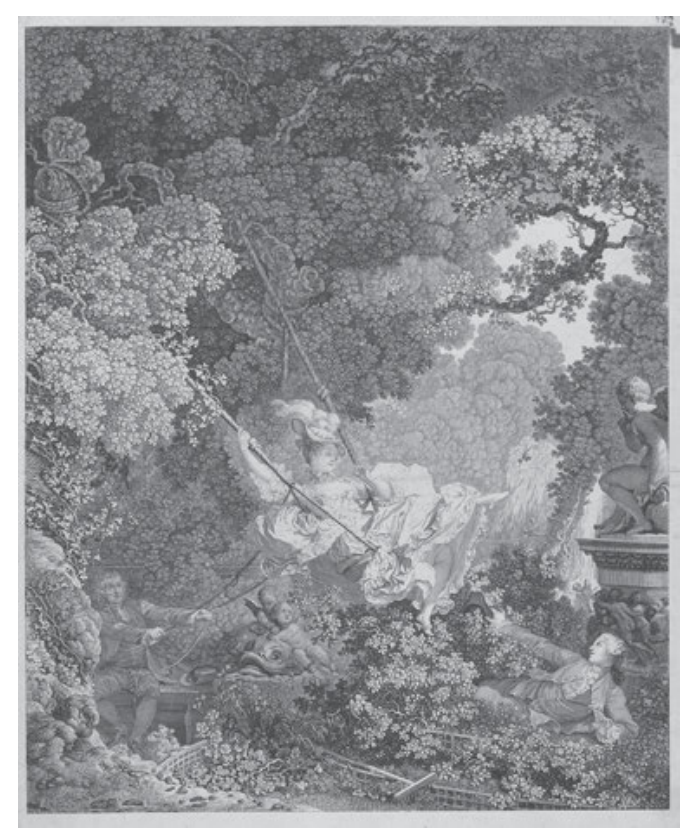

Abb. 38: „Les Hazards heureux de l'Escarpolette“, Stich von Nicolas de Launay nach Jean-Honoré Fragonard, um 1782.

Mit größter ästhetischer Präzision baut dieser poeta doctus sein eigenes Universum aus Worten und Texten auf und verstrickt seine Leserschaft in ein heiteres Spiel von Liebe und Lesen. So stellt sich sogleich auf dieser Ebene selbstverständlich eine Beziehung her zwischen der Funktion des Autors und Schriftstellers und jener des Demiurgen Cosimo, der sich ebenfalls schöpferisch eine eigene Welt schafft mit ihren eigenen Gesetzen, Verfahren und Gegenständen, die gleichwohl wie die des literarischen Autors nicht gänzlich von der Welt allgemein zugänglicher Natur getrennt ist. Denn diese Welt aus Buchstaben ist keineswegs scharf abgegrenzt von den gemeinhin gültigen Gesetzen und den damit zusammenhängenden Lebenserfahrungen sowie von all dem, was wir bisweilen ein wenig vorschnell als „Realität“ oder außersprachliche Wirklichkeit zu bezeichnen pflegen. Diese poetologisch-demiurgische Verwandtschaft zwischen den beiden Weltenschöpfern gilt es natürlich im Auge zu behalten und auf jene Immanenz des Textes und seine Selbstreferentialität zu beziehen, die in grundlegender Weise zu den Merkmalen von Literaturen im Zeichen der Postmoderne zählt. Diese 
Elemente machen zugleich aber auch auf die Komplexität aller Lesevorgänge in Calvinos Romantext aufmerksam.

Im Kontext dieser Überlegungen möchte ich zugleich auf die Tatsache aufmerksam machen, dass Italo Calvino seinen Roman in sehr unterschiedlichen Fassungen veröffentlicht hat, eine Tatsache, die einen gewissen Tonio Cavilla dazu bewog, ein Vorwort für eine Ausgabe dieses Textes in der Reihe Letture per la Scuola Media zu verfassen, wo wir die folgenden Bemerkungen lesen. An dieser Stelle, in dieser Ausgabe, wird Italo Calvino zum Leser seiner selbst und gestaltet sich selbst als eine Leserfigur, die wir gerade im Zeichen der Postmoderne sehr häufig finden und die eine sehr spezifische Form der Verschränkung von Lesen und Schreiben in Zeiten einer akuten Selbstreferentialität darstellt.

\begin{abstract}
Der Baron auf den Bäumen wurde nicht ausdrücklich für ein sehr junges Publikum geschrieben; aber seine Filiationen zu den Klassikern der Kindheit, das abenteuerbeladene Kaleidoskop, der geschichtliche Hintergrund, die Klarheit und Genauigkeit des Schreibens, die moralisierende Art stellten allesamt Gründe dar, die das Buch dazu drängten, sein Lesepublikum auch bei den Jugendlichen zu suchen. In der Tat zog der Autor selbst aus dem Text, wie er erstmals 1957 publiziert worden war, mit einem geringen Aufwand an Schnitten und Verbindungen die Ausgabe für Jugendliche (l'edizione per ragazzi) heraus (von etwas verkürztem Umfang im Vergleich zur editio maior), die dann mit farbigen Illustrationen 1959 erschien und pünktlich (wie die editio maior) jedes Jahr nach einer Neuauflage verlangte. Viele Schulklassen der Scuole Medie haben sie als Lektüretext übernommen, und zwar so sehr, dass eine neue Ausgabe nötig wurde, die ausdrücklich für die Schule konzipiert wurde, das heißt jene, die wir heute vorstellen. ${ }^{3}$
\end{abstract}

Halten wir zunächst einmal fest, dass Calvinos alter ego Tonio Cavilla als erfundene Leserfigur einen eher umständlichen Stil pflegt. Denn dieser Schulausgabe ist ein wenig didaktisch und oberlehrerhaft die nachfolgende „Nota dell'editore“ vorangestellt: „Zwischen dem eigenen Buch und sich selbst wollte Italo Calvino die Figur eines pingelig genauen Dozenten und Pädagogen, Tonio Cavilla, einführen, der den Text mit kritischer Distanz und jener Seriosität, die dem Autor notwendig schienen, analysiert und kommentiert hat. " ${ }^{4}$ Calvino macht sich selbst also einen Spaß daraus, nicht nur seine Leserfiguren zu schaffen, sondern auch noch zu kommentieren und einzuordnen. So bettet er seinen Roman in ein hochkomplexes Netz verschiedener Leseprozesse ein, die wir als Leserinnen und Leser wiederum erforschen können.

Was folglich Tonio Cavilla mit der dem Kritiker eigenen Geste der Selbstzufriedenheit vorstellt, ist eine italienische Schulbuchausgabe, die wir in der Folge parallel zu unserer „offiziellen“ und kompletten, ungekürzten Ausgabe benutzen

3 Calvino, Italo: Il barone rampante 1965, S. 11.

4 Ebda., S. 4. 
wollen, um aus den beiden Fassungen sowie den von Tonio Cavilla eingebrachten Kommentaren und Fußnoten zusätzliche Hinweise und Aspekte herauszufiltern. Sie sollen uns nicht nur über den Text selbst, sondern auch über neue Formen von Selbstreferentialität oder Selbstbezüglichkeit (in denen der Autor sich selbst zum Anderen, zum Leser, macht) aufklären. Zugleich wird die gesellschaftliche Praxis, das Lesen durch bestimmte Institutionen - etwa die der Schule - anzuleiten, sehr schön dokumentiert und bisweilen ironisch hinterfragt. Auch hier also zeigt sich, auf welch direkte und doch komplexe Weise das Lesen mit dem Leben verbunden ist und nicht zuletzt auch gesellschaftlich kontrolliert wird. Dass man bei dieser Lesekontrolle die Liebe und insbesondere die Liebesszenen in den Scuole Medie etwas unterschlagen hat, überrascht nicht wirklich.

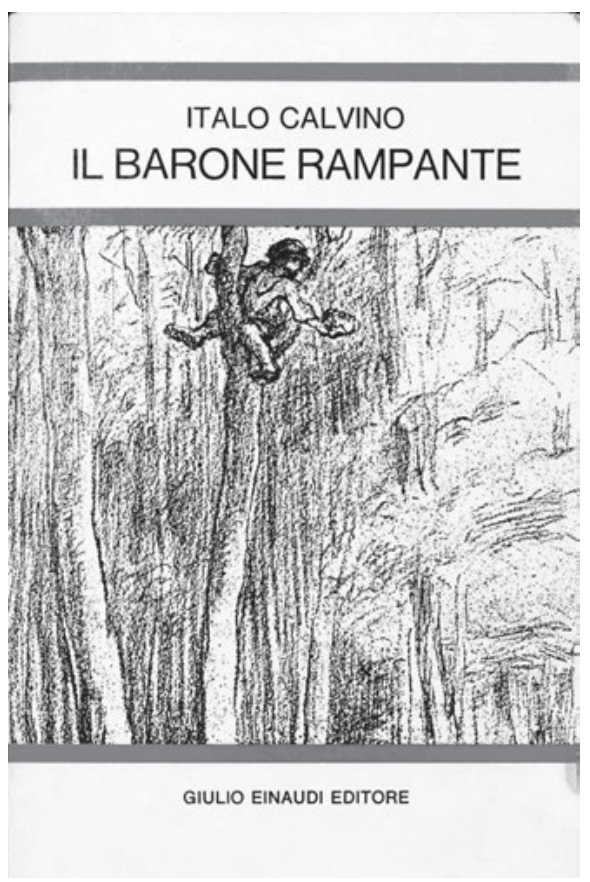

Abb. 39: Cover der Neuausgabe von Italo Calvinos /l barone rampante. Prefazione $e$ note di Tonio Cavilla.

Im Verlauf des Romans beweist Cosimo, welch starken Charakter er besitzt und wie wenig er sich von seiner Umwelt bezüglich seines Entschlusses, auf den Bäumen zu leben, beeinflussen lässt. Keiner kann den jungen wie den älter werdenden Baron seit dem missglückten Versuch Violas, ihn von der Schaukel zu schubsen, wieder auf den Boden unserer Welt und ihrer Gewohnheiten zurückholen - nicht einmal mehr der Tod, wie das Ende dieses Romans uns zeigen wird. Nicht die kleinen, aus armen Familien stammenden und zerlumpten Obstdiebe 
können es, denen der junge Adlige nach Kräften hilft; nicht sein Vater, der Baron, der ihn einst des Tisches verwies, und nicht die Schwester Battista, die mit ihren Schneckenmartyrien Ausgangspunkt für den Weg Cosimos war und die ihn später mit Hilfe von Vogelleim auf seinem Ast festkleben will. Doch ihr gehen nur eine Reihe armer Vögel und Falter in die Falle. Keine der vielen erfundenen oder historischen Gestalten wie Napoleon Bonaparte, die im Verlaufe seines langen Lebens jenem berühmt gewordenen Baron auf den Bäumen ihre Aufwartung machen wollen, vermag es, diesen von seinem Entschluss abzubringen. Denn der steht ein für alle Mal fest!

Der von seiner Entscheidung, alles in seinem Leben auf den Bäumen zu verrichten, nie mehr abrückende Baron ist von der Welt der „normalen“ Menschen ebenso unwiederbringlich entrückt wie dieser Welt verbunden, von der ihn ja nur wenige Meter trennen. Aber wie der Romantext uns dies sehr schön beschreibt: Es gibt Reisen, die nur über wenige Meter führen und doch ohne jede Rückkehr sind. Nicht der Versuch einer Teufelsaustreibung durch den Hauslehrer und Abbé Fauchelafleur, nicht eine im Auftrag des Vaters durchgeführte Treibjagd können fürderhin den jungen Mann davon abhalten, eine Welt aufzubauen, die doch eigentümlich um den Garten einer schönen Villa gruppiert, von seiner melancholischen Sehnsucht nach diesem Ort und dem jungen, hübschen Mädchen zentriert wird.

Nach vielerlei Abenteuern, welche der Baron $\mathrm{zu}$ bestehen hat und die diesen Text in die Tradition der Kinder- und Jugendliteratur stellen, und nach der Entfaltung zunehmend komplexer gedachter gesellschaftlicher Einsichten, die deutlich auf die gesellschaftskritische Stoßrichtung der französischen Aufklärer, aber auch auf die aktuelle Situation Italiens bezogen sind, nähern wir uns einer für das gesamte Buch wichtigen Episode, die für unsere Lektüre von großer Bedeutung ist. Sie steht wiederum im Zeichen der Freiheit und ist erneut mit der Problematik von Armut und Besitz verbunden. Sie konfrontiert den mittlerweile berühmten Cosimo mit einem nicht weniger berühmten Bewohner des Waldes, dem von ihm selbst schon mehrfach aufgerufenen Briganten Gian dei Brughi, dessen Stoppelhaare und Stoppelbart so rot wie das Heidekraut sind, das er in seinem Namen trägt. Doch diese Konfrontation erweist sich als eine höchst ungleiche.

Das erste Zusammentreffen zwischen Cosimo und Gian dei Brughi erfolgt im Zeichen der Lektüre: Denn Cosimo sitzt gerade bequem auf einem Nussbaum und ist mit Lesen beschäftigt, als der große Brigant von 2 Häschern verfolgt in den Wald stürmt und von Cosimo, der die Ordnungshüter in die Irre leitet, vor weiterer Verfolgung geschützt wird. Cosimo steht der herrschenden Ordnung, dem feudalistischen Ancien Régime, kritisch gegenüber und hat stets ein Herz für die armen Leute, die sich irgendwie durchzuschlagen versuchen. Es ist freilich auch denkbar, dass seine Handlungsweise von seiner 
Lektüre nicht unbeeinflusst geblieben war, denn Cosimo las gerade den Gil Blas von Lesage, einen französischen Schelmenroman, der im 18. Jahrhundert die spanische novela picaresca des 16 . und 17. Jahrhunderts philosophisch wie literarisch umfunktionierte und nach Frankreich holte. Der französische Autor wusste sein französisches Publikum wie das aufgeklärte Lesepublikum seiner Zeit mit allerlei schönen philosophischen Äußerungen anstelle jener moralités superflues zu versorgen, die die Leser des 18. Jahrhunderts laut Lesage so sehr störten.

Wir sehen deutlich: Cosimo ist ein sehr aufmerksamer und fast idealer Leser. Seine Lektüre bleibt niemals ohne Rückwirkung auf sein alltägliches Leben. Dies gilt auch für die Beziehung zu dem großen Räuber und Verteidiger der Armen. Denn auf das Ende der Relation zwischen beiden wird gleich zu Beginn ihres ersten Treffens angespielt, wirft Cosimo doch Gian dei Brughi ein Seil herunter, damit dieser sich auf einen Baum hochziehen und in Sicherheit bringen kann. Am Ende des Romans wird Gian dei Brughi als ein Opfer der Lektüre von einem Baum herunterhängen - eine fürwahr schicksalhafte Begegnung zumindest für den roten Briganten. Denn sein Fehler, sein Vergehen, war die Abhängigkeit von Lektüren, die für ihn zu einer Droge wurden: Nichts konnte seinem hemmungslosen Verschlingen von Büchern aller Art Einhalt gebieten. So wurde er letztlich für die Ordnungshüter ein leichter Fall, verlor er doch die Fähigkeit, sich ihnen immer und immer wieder zu entziehen. Ja, Lesen ist gefährlich! Der Brigant reiht sich in die lange Liste von Leseopfern, von Opfern der Lektüre ein, zu deren bekanntesten - neben Paolo und Francesca - zweifellos Don Quijote und Emma Bovary zählen.

Dabei fing alles so harmlos an. Das erste Gespräch zwischen beiden beginnt mit der höflichen Frage und Bitte des geretteten Briganten, ob Cosimo ihm das Buch, das er gerade lese und von dem er nur selten einmal aufblicke, einmal ausleihen könne. Er müsse sich tagelang versteckt halten und wisse dann nie, was er tun solle. Also fürwahr: die idealen Voraussetzungen für eine intensive Lektüre, zu der es - im Gegensatz zu vielen anderen Grundsituationen - keiner zusätzlichen Motivation mehr bedarf. Kurz und gut, Gian dei Brughi hat bald schon Lesages remake ausgelesen und leiht sich bei Cosimo andere Bücher, die dieser aus der väterlichen Bibliothek, zunehmend aber auch von einem jüdischen Buchhändler, der ihn mit den Schriften der Aufklärer versorgt, bezieht. Gian dei Brughi liest also, was man im 18. Jahrhundert eben so las.

Doch bald schon entwickelt er mit stetig anwachsender Lektüre einen eigenen Geschmack und will sich keineswegs mit dumpfen Liebesgeschichten abspeisen lassen. Es kommt, wie es nicht anders kommen kann: Gian dei Brughi befällt eine ungeheure Lesewut und er verschlingt ein Buch nach dem anderen, 
wobei er manche Bücher an einem einzigen Tag herunterliest. Längst ist für Gian dei Brughi zum alleinigen Hauptzweck die Lektüre und nicht mehr der Raub geworden, wobei auch der Lesekonsum Cosimos in jener Zeit unter dem Einfluss des Briganten deutlich zunimmt. Während Cosimo von einer Leidenschaft für die Literatur und für das gesamte menschliche Leben ergriffen wird, so dass er die Lektürezeiten beim Schein einer Laterne auch in die Nachtstunden ausdehnt, entwickelt sich Gian dei Brughi zu einem Opfer seiner Lesewut, wird gleichsam ein Raub der Bücher, die nun ihn verschlingen.

Gian dei Brughi begeistert sich - wie viele andere Leser seiner Zeit - insbesondere für die Romane des Briten Samuel Richardson, der ihn weitaus mehr fesselt (wörtlich gemeint) als etwa der Télémaque von Fénelon. Wir selbst mögen ihm dies verzeihen, nicht aber seine Räuberbrüder, die zunehmend gefährdet sind, wird doch der Wald, in dem auch sie wohnen, immer intensiver von Polizei und Sbirren auf der Suche nach Gian dei Brughi durchstreift, was sie in der Ausübung ihres eigenen noblen Handwerks sehr beeinträchtigt.

So versuchen zwei Vertreter dieser Räuber, Gian dei Brughi wieder für dessen eigentlichen Beruf zu interessieren und ihn auf den rechten Weg als Räuberhauptmann zurückzuführen. Doch dieser hat sich grundsätzlich verändert: Er sehnt sich nach einem geregelten häuslichen Leben mit festem Tagesablauf und ergreift, wo er doch früher vor nichts Angst hatte, nun plötzlich selbst vor Spinnen die Flucht. Für nichts interessiert er sich mehr, was außerhalb der Bücherwelt liegt. Ein hoffnungsloser Fall!

So gelingt es den beiden Kumpanen auch nur, Gian dei Brughi zu einem geplanten Raubzug zu pressen, indem sie damit drohen, die letzten Seiten des Romans Samuel Richardsons, den Gian dei Brughi gerade liest - nämlich Clarissa Harlowe -, schön nacheinander auszureißen. Mit dem Ende würden sie anfangen, falls er nicht mitmache. Da bleibt dem Briganten nichts anderes übrig. Gian dei Brughi ist von jener Clarissa begeistert, da sie ihre Rolle als verfolgte Unschuld in einer Konstellation spielt, welche der Marquis de Sade in gänzlich anderer Weise auch für seine Justine ou la vertu persécutée nutzte. Nichts kann ihn daher vom Lesen abhalten und er willigt lediglich ein, seine Lektüre nur kurz zu unterbrechen.

Allein unter dem Versprechen, sein Buch gleich nach dem Raub sofort wieder $\mathrm{zu}$ bekommen und weiterlesen zu dürfen, lässt sich Gian auf den Raubzug ein, tritt dann aber selbst geradezu als fiktionale Gestalt auf, die sich nicht ernstnehmen kann, und wird folgerichtig sehr schnell von den wesentlich fester im Leben stehenden, vermeintlichen Opfern gefangengesetzt. Das Ende seines Lebens und damit auch seines Lesens ist nahe. Gian dei Brughi hat aus der Literatur gelernt, sich vor allem von außen zu betrachten, sich also gleichsam als eine Figur eines 
gerade gelesenen Romans zu begreifen. Dies verändert seine Einstellung zum Leben in grundlegender Weise - und natürlich auch zum Tod.

Dabei kümmert es ihn wenig, dass man ihn der verschiedensten Überfälle anklagt und in einen Turm wirft, solange er nur hinter den Gittern seines Gefängnisses noch die Stimme Cosimos hören kann, der ihm auf einem Baum sitzend laut die Lieblingsromane vorliest. Dies ist wahre Hingabe: Cosimo macht sich gleichsam zum Lesesklaven für einen Briganten, wobei er als Vorleser vorbildlich agiert. Ganz nebenbei führt uns Italo Calvino damit eine weitere historische Modalität der Lektüre in actio vor. Wahre Leselust - in etwa so, wie von einem nicht unbekannten Vertreter unseres Faches einmal behauptet werden konnte, er werde selbst in seinem Sarg noch ein offenes Buch in Händen halten.

In jedem Falle bringt Cosimo Richardsons Clarissa nun für Gian dei Brughi buchstäblich zu Ende, worauf - weiß Cosimo eigentlich um seine schuldhafte intertextuelle Verstrickung? - ein neuer Roman, diesmal von Henry Fielding, folgt. Die Tage des Prozesses von Gian dei Brughi sind gekommen; doch denkt dieser nur an das mögliche Ende dieses seines letzten zu Lebzeiten gelesenen Romans. Bevor der Roman zu Ende ist, kommt jedoch der Tag der Hinrichtung, ein wirklich grausiges Schicksal für einen passionierten Leser. Doch hören wir selbst das Ende des zwölften Kapitels:

Bevor der Roman zu Ende war, kam der Tag der Hinrichtung. Auf dem Karren, begleitet von einem Mönch, trat Gian dei Brughi seine letzte Reise zu Lebzeiten an. Die Hinrichtungen wurden in Ombrosa an einer hohen Eiche mitten auf dem Platz vollzogen. Ringsum bildete das gesamte Volk einen Kreis.

Als er das Seil an seinem Hals hatte, hörte Gian dei Brughi einen Pfiff, der aus den Zweigen kam. Er hob den Kopf. Cosimo war's, mit dem geschlossenen Buch.

- Sag' mir, wie es zu Ende geht, meinte der Verurteilte.

- Es tut mir leid, Dir das sagen zu müssen, Gian, antwortete Cosimo, aber Jonathan endet am Galgen.

- Danke, Cosimo, so sei es auch mit mir! Auf Wiedersehen! - und er selbst kickte die Leiter weg und ward erdrosselt.

Als sein Körper zu zappeln aufgehört hatte, ging die Menge weg. Cosimo blieb die Nacht über rittlings auf dem Zweig, von dem der Hingerichtete baumelte. Immer dann, wenn ein Rabe in die Nähe kam, um dem Kadaver die Augen oder die Nase zu zerhacken, verjagte ihn Cosimo mit seinem Dreispitz. ${ }^{5}$

Das Spiel ist aus - und mit ihm die Lektüre! Ein schreckliches und zugleich doch tröstliches Ende des Briganten, ganz im Einklang mit dem letzten von ihm

5 Ebda., S. 148. 
gelesenen, gehörten Roman. Denn hier hält nicht nur ein guter Freund, sondern zugleich auch ein gutes Buch dem Gehenkten die Totenwache und erweist ihm damit die letzte Ehre. Ja mehr noch: Henry Fieldings Jonathan Wild bildet nicht nur das Modell, dem Gian dei Brughi seinerseits nacheifert. Dieser wird selbst zum Hauptdarsteller einer Aufführung, die sein Leben beendet und durch ihre intertextuellen Verweise in ein Stück Fiktion verwandelt. Der Brigant tritt gleichsam aus seinem Räuberleben und wird zum Protagonisten eines Romans, liest somit zugleich sein eigenes Lebensende. Lektüre und Ende des Lebens fallen ineinander.

Wäre Gian dei Brughi noch rechtzeitig geklont worden, er könnte wohl doch keinerlei Trost aus der Tatsache ziehen, dass seine Verdoppelung dazu führt, dass sein Doppelgänger und nicht er selbst überleben wird. In obenstehender Passage aber verwandelt sich jemand in den Doppelgänger einer literarischen Figur und entrückt sich auf diese Weise selbst einem banalen irdischen Schicksal. Denn in diesem Zitat wird die Aufnahme des Helden in einen literarischen Raum gefeiert, dem er sich selbst durch intensive Lektüre zuordnete. Er stirbt als zufriedenes Opfer einer Lektüre, der er immer weitere Teile seines Lebens schenkte, bis das Lesen endgültig an die Stelle des Lebens rückte und selbst zum literarischen Leben wurde.

Kein Wunder also, dass uns die literarische Figur Gian dei Brughi so sehr besticht: Sie ist ein gutes Stück Literatur. Indem sie sich selbst als ein solches erkennt und das geschlossene Buch als ein Stück symbolischen Bewusstseins dafür gewinnt, noch ein Bewusstsein für den eigenen Tod zu entwickeln, wird nicht nur das Buch zum wahren, zum wirklicheren und höheren Leben, sondern das Leben selbst zum wahren und wirklicheren Buch. Und wie in einer richtigen Geschichte gibt es auch hier noch ein Postskriptum, insoweit es einen trauernden Gast gibt, dessen Bild sorgender Anteilnahme dem Gehenkten gleichsam doppelt nachgeschickt wird. Denn Cosimo hält seinem Freund die Treue und liest bis zum bitter-süßen Ende.

So bleiben nicht nur die Nase, sondern auch die Augen, welche so begierig die Seiten der vorausgehenden Romane lasen, verschont von der Zerstörung durch die Natur, verschont von dem, was sich diese Natur gleichsam zurückholt. „Polvo serás / mas polvo enamorado.“ Denn noch im Tode des Briganten wird deutlich, dass dieser das Lesen über alles liebte. So ist die Liebe nicht nur ein bloßer Gegenstand der Lektüre: Lesen wird selbst zum Gegenstand der Liebe.

Die Reise - und auch hier taucht die Reisemetaphorik in der Literatur wieder auf - des Gian dei Brughi auf der Erde ist zu Ende. Doch ist dies noch nicht gleichbedeutend mit dem Ende der Reise auf Ebene der Literatur. In der Figur des Briganten verschränken sich Leben und Lesen $\mathrm{zu}$ einer sich wechselseitig 
verbindenden und bedingenden Schicksalsgemeinschaft des eigentlichen und des wahren Lebens als eines Lesens. Bliebe $\mathrm{zu}$ fragen, ob der Literaturkritiker Tonio Cavilla dies ähnlich sehen kann.

In der Tat finden wir in der italienischen Schulbuchausgabe für die Scuole Medie einen aufschlussreichen Kommentar zum zwölften Kapitel. Erneut äußert sich der reale Autor in der Figur eines pedantischen, lehrerhaften Lesers über eine Leserfigur als Leser seines eigenen Buches:

\begin{abstract}
Das zwölfte Kapitel ist von den vorangehenden gänzlich verschieden und bildet gleichsam eine Erzählung für sich: eine Art satirischen Apolog unter den Auswirkungen der Kultur, gleichsam eine „philosophische Erzählung“ im Stile des 18. Jahrhunderts (aber konstruiert mittels einer narrativen Technik der Moderne, mit Dialogen). Auch die einzelnen Elemente der Erzählung entstammen dem 18. Jahrhundert: das traditionelle Motiv der Briganten (eine Mythe, die hier ins Lächerliche gezogen wird: der legendäre Brigant ist ein armer Tunichtgut, der sich nichts anderes erträumt als sentimentale Lektüren) und die Woge des Romans, der schon im 18. Jahrhundert eine ganze Industrie zum Leben erweckte. Der Kontrakt zwischen dem ehemaligen Briganten, der sich darauf versteift, Romane zu lesen, und einem Cosimo, der durch die Lektüre zu einem verantwortungsvollen und aktiven Menschen wird, mag den Verbund repräsentieren zwischen einer Lektüre als Evasion und Lektüre als Bildung. Aber die wahre Funktion dieses Kapitels besteht innerhalb der Entwicklung des Romans darin, uns über die Lektüren von Cosimo Rechenschaft abzulegen, ein Motiv, das sogleich wichtig werden wird. Ungeachtet der Feinheit der Fabel wird das Kapitel von einer gewissen Kühle charakterisiert (denn angesichts des Todes des Briganten bleibt nur ein visuelles Bild); wir sind weit entfernt von der Fülle der Darstellungen der ersten Kapitel des Buches. ${ }^{6}$
\end{abstract}

Italo Calvino erweist sich in diesen Passagen einmal mehr als ein aufmerksamer Leser und kritischer Kommentator seiner eigenen Texte. Denn Sie merken: Das Spiel mit dem eigenen Text schließt nicht zuletzt auch die Kritik dieses Textes mit ein. Ob wir allerdings hier von einer freddezza, von einer Kühle und Oberflächlichkeit sprechen können, sei einmal dahingestellt. Entscheidend für diese Äußerungen scheint mir vielmehr jenseits aller Versuche, dem (vorwiegend jungen) Publikum Hinweise auf die konkrete Textgestalt und deren historische Hintergründe zu geben, eine Auseinandersetzung mit dem eigenen Text dergestalt zu führen, dass literarische und metaliterarische Gestaltung miteinander in einen engen Dialog eintreten, der nicht nur die Selbstdistanzierung, sondern vor allem auch das Weiterschreiben am eigenen Text beinhaltet. Denn Italo Calvino schreibt nicht allein über seinen eigenen Text, er schreibt diesen Text vor allem weiter und diskutiert dessen Bedeutungsebenen mit didaktischer Emphase, aber auch ironischer Distanz.

6 Cavilla, Tonio: Nota al dodicesimo capitolo. In: Calvino, Italo: Il barone rampante 1965, S. 149. 
Dadurch entsteht ein neues Textgewebe. Die Verbindung zwischen literarischer und metaliterarischer Ebene, die in diesen Note und Fußnoten Tonio Cavillas auf paratextuelle Weise gelöst ist, wird freilich im weiteren Verlauf der literarischen Entwicklung Calvinos (und eines Großteils zeitgenössischer Autoren) vom Paratext in den eigentlichen Text selbst hineinverlagert, so dass literarische und metaliterarische Ebenen bisweilen unentwirrbar miteinander verbunden sind. Zugleich schlägt Italo Calvino alias Tonio Cavilla, bei aller Satire über die Schreibweise der Literaturkritik, auch eben jenes Thema an, das von zentraler Bedeutung für unsere Vorlesung über LiebeLesen ist: die zentrale Rolle des Lesens und der Lektürepraktiken, die Selbstbezüglichkeit der Literatur auf die Literatur, die intertextuelle Immanenz ihres eigenen Sich-Selbst-Schreibens und die grundlegende Neubewertung der Lektüre in all ihren Formen und Positionen als letztlich texterzeugende aktive und kreative Praxis.

Es geht folglich gerade nicht um die Lektüre als Evasion, sondern um das Lesen als Produktion des Textes, als textgenerierende Praxis. Wir haben auch mit großer Aufmerksamkeit wahrgenommen, dass wir Gian dei Brughis Lektüre keineswegs nur als Evasion und Flucht aus der Realität charakterisieren können. Denn sie ist viel mehr: eine konstitutive Grundlage der Textproduktion wie des Lebens selbst. Lesen und Leben sind aufs Engste miteinander verbunden - und so ist es auch die Liebe. Wir haben ja bereits gesehen, welch grundlegende Bedeutung Calvino der Lektüre beziehungsweise dem Lektüreakt in seinem Roman Se una notte d'inverno un viaggiatore zukommen ließ. Aber schon einige Jahrzehnte früher, in Il barone rampante, tritt diese Beziehung bei ihm offen $z u$ Tage.

Lassen Sie uns aber unsere Auseinandersetzung mit diesem Calvino-Roman der fünfziger Jahre abschließen. Denn es folgt ein sehr bedeutungsvolles Kapitel, das in der Schulbuchausgabe den Titel „La foresta dei libri“ trägt und damit die Metaphorik der Bäume und des Blattwerks explizit auf den Bereich des literarischen Dickichts, der Beziehungen zwischen verschiedenen Büchern untereinander, überträgt. Ich werde auf diese Metaphorik mit Blick auf das Romanende nochmals zurückkommen, aber bereits an dieser Stelle darauf hinweisen, dass nun ein literarischer Raum aufgebaut wird, der ganz an der Diegese des Romans ausgerichtet ist. So wird die Bücherwelt im Kopf Cosimos rekonstruiert. Aus ihr entspringen letztlich die konkreten Handlungen im „wahren Leben“ dieser literarischen Figur.

Auch hieran können Sie erkennen, welche Bedeutung und welche Kraft der Lektüre im Roman zuerkannt werden. In jedem Falle geht es um das Lesen und Schreiben und deren Verquickung: also um die Blätter, die die Welt bedeuten. Der Schüler Cosimo ist jedenfalls längst zum Lehrer des Hauslehrers, des Abbé Fauchelafleur geworden und korrespondiert mit Schriftstellern und Philosophen wie 
Denis Diderot oder Jean-Jacques Rousseau, liest die Encyclopédie oder die Texte des Baron de Lahontan. Die zentralen philosophisch-geistigen Auseinandersetzungen des 18. Jahrhunderts werden in die Romandiegese eingeblendet: ebenso im Bereich der Anthropologie wie der Gesellschaftstheorie, im Bereich der Liebeswie der Gotteskonzeption, hinsichtlich der wünschenswerten Regierungsform wie der individuellen Lebenspraxis. Insoweit geht hier ein ganzes gebildetes Stichwortregister kunstvoll in die diegetische Ausgestaltung des Romans ein, der selbstverständlich über einen intradiegetischen Erzähler verfügt, welcher eine Vielzahl zusätzlicher Erfahrungen und Einsichten in seinen Text miteinbringen kann. Leichtigkeit und Lebendigkeit von Il barone rampante täuschen: Der Roman ist mit Anspielungen und Verweisen, mit impliziten Interpretationen und Kommentaren übervoll.

Cosimo ist mittlerweile achtzehn Jahre alt; und so kommt der Baron di Rondò vorbeigeritten, um eine Art Aussöhnung zu finden und den Generationenvertrag im Adelshause fortzuschreiben. Er schnallt dem Sohn den Degen eines Barons um, obwohl dieser auf dem Baum sitzt und auf die Frage, ob er sich denn der Tatsache bewusst sei, ein Baron di Rondò zu sein, antwortet, er sei sich vor allem der Tatsache bewusst, ein Mensch zu sein und wolle alles in seinen Kräften Stehende tun, um sich dieses Namens „Mensch“ würdig zu erweisen.

Trotz der Radikalität seines Entschlusses, auf die Bäume zu klettern und zeit seines Lebens nicht mehr herunterzukommen, ist Cosimo letztlich doch ein auf Harmonie und Gleichgewicht abzielender Bürger Rondò, ein eher sanfter Revolutionär, dem es nicht um die Zerstörung, sondern vielmehr um die konstruktive Dimension des Lebens und um eine auf Ausgleich gerichtete Konvivenz geht. Noch einmal: Es ist an dieser Stelle nicht möglich, den einzelnen, insbesondere intertextuell sehr dicht gewobenen Kapiteln sowie den jeweiligen unterhaltsamen Abenteuern Cosimos im Detail nachzugehen, $\mathrm{zu}$ weit würde uns dies von unserem eigentlichen Thema der Vorlesung wegführen. Fehlen darf aber nicht der Verweis auf die Tatsache, dass Cosimo zunehmend nicht nur Literatur konsumiert und produktiv verarbeitet, sondern selbst zum Geschichtenerzähler wird, zum barone contastorie, wie der Titel des sechzehnten Kapitels der Schulbuchausgabe es andeutet. Dies ist eine bedeutungsvolle Wendung im plot des Romans.

Die Widersprüchlichkeit seiner storie ist dabei weniger interessant als die Lust, derartige Geschichten zu verfassen und damit ein Publikum zu belehren und $\mathrm{zu}$ unterhalten, das möglichst breit aufgestellt ist und eine demokratische Öffentlichkeit unserer Tage vorwegnimmt. Immer stärker kommt der barone rampante damit in eine aufschlussreiche Nähe zu jenem Lügenbaron, der in der deutschen Kulturgeschichte noch immer unvergessen ist und unter dem Namen des Barons von Münchhausen heute noch fast jedem Kind geläufig ist. Cosimo 
entwickelt eine eigentümliche Lust am Erfinden derartiger Geschichten, während der Erzähler jener Geschichte, die wir lesen, Biagio, seinerseits versucht, nicht aus dem Tritt zu kommen und den wahren Kern oder den roten Faden nicht zu verlieren. Bisweilen blendet er die Erzählungen seines Bruders ein, wenn er selbst nicht so genau anzugeben weiß, wie sich eine Geschichte wirklich ereignet hat. Biagio steht stets im Schatten seines Bruders.

Für Cosimo freilich ist das Erzählen von Geschichten nichts anderes als die Suche nach einem Publikum. Und diese Suche nach Zuhörern ist letztlich nur ein Surrogat für die bedauernswerte Tatsache, dass er noch immer nicht die Liebe in all ihren Formen kennengelernt hat. Wir nähern uns also jenem Themenbereich erotischer Liebe an, der bereits auf der Schaukel angedeutet worden war und der sich in der Schulbuchausgabe des Barone rampante nicht findet. Doch die Liebe ist das zweite große Thema des Romans. Auch in Italien versucht man eben, in der Schule die ohnehin altersbedingt verwirrten Gemüter nicht noch weiter zu verwirren. An der Universität und in unserer Vorlesung aber sei es mir erlaubt, ein derartiges Thema nicht zu verschweigen, ist doch die erotische Liebe dem wahren Lesepublikum ein vertrauter Gegenstand, welcher niemanden mehr aus der Fassung bringen kann. Aber wie lernt unser Cosimo die Liebe kennen?

Cosimo ist, wie wir sahen, ein großer Leser und dabei auch ein Verschlinger von Liebesromanen, die in der zweiten Hälfte des 18. Jahrhunderts en vogue waren und ein breites Lesepublikum erreichten. Cosimo lernt die Liebesnormen und die Liebesformen vermittelt durch die Lektüre, durch ein wahres LiebeLesen. Sie fragen sich jetzt bestimmt, wie sich das Leben und Lesen auf den Bäumen mit der Liebe verträgt! Nun, es gibt auch noch eine zweite Quelle eines Liebeswissens, die sich mit der erstgenannten vermischt.

Denn Cosimo lernt die erotische, körperliche Liebe in Olivabassa kennen, einem Örtchen, wohin sich eine Reihe spanischer Edelleute zurückgezogen hat, die von Carlos III., dem Bourbonen und Reformkönig, zusammen mit den Jesuiten aus Spanien und seinen Besitztümern vertrieben worden war. Da sie jedoch ihren Fuß nicht auf fremden Boden setzen konnten, lebten sie auf Bäumen, auch wenn sie im Gegensatz zu Cosimo nicht autark blieben, sondern sich von mit Leitern bewaffneten Bürgern und Bauern bedienen ließen. In diesem Ambiente trifft Cosimo ein hübsches spanisches Mädchen mit grünen Augen, das auf den Namen Ursula hört und mit ihm - eng wie zwei Vögel aneinandergepresst - auf einem Zweig sitzt, bis sich geradezu zwangsläufig ein Kuss löst. So fängt es also an, und es bleibt nicht dabei!

Aber Cosimo verliert seine Ursula wieder, die ihn in für ihn völlig neue Liebespraktiken einführte, als die spanischen Adligen begnadigt werden, nach Spanien zurückkehren dürfen und auch die junge Ursula mit Gewalt in eine Kutsche in 
Richtung Spanien zerren. Immerhin: Cosimo ist nun aufgeklärt und wird zur Attraktion aller hübschen Mädchen, die bis zu diesem Zeitpunkt die Erfahrung der Liebe höchstens in einer Entfernung vom Fußboden machen konnten, die nicht höher als etwa ein Meter ist. Der Baron auf den Bäumen streicht des Nachts wie eine Katze miauend um die kleine Stadt Ombrosa; und er gilt bald bei Alt und Jung als Vater all jener Kinder, für deren Vaterschaft niemand geradestehen will. Immerhin: Etwas Wahres wird schon daran gewesen sein, jagt ihm ein eifersüchtiger Rivale doch auch einmal eine Ladung Schrot in die werte Kehrseite. Während der Rekonvaleszenz entwirft Cosimo das Bild einer Gesellschaft, die auf den Bäumen lebt, wobei er allerlei erotische Histörchen, der Zeitsitte gemäß, in das Kapitel über das Eherecht einstreut. An diesem Punkt verbindet sich der Strang der Aufklärungsphilosophie mit jenem des libertinage höfischer Prägung, der nicht ohne eine eigene Liebesphilosophie im Boudoir - ohne eine Philosophie dans le boudoir, um auf den Titel des Marquis de Sade anzuspielen - auskam.

Doch was ist mit der „wahren Liebe“ Cosimos? Nun, sie lässt nicht mehr lange auf sich warten. Eines schönen Tages ist nämlich die schöne Viola, die den greisen Fürsten Tolemaico ein Jahr vor dessen Tod geheiratet hat und nun als Witwe lustig und freizügig leben kann, wieder zu ihren Besitzungen zurückgekommen und nimmt die alte Villa und den Garten derer von Ondariva erneut in Besitz. Beide Königskinder sehen sich wieder, und sie tun dies natürlich am Ort der Schaukel. Ihre künftige Beziehung wird nun in deren Zeichen stehen. Viola ist nicht weniger schauklig und verwirrend als früher: Sie ist noch immer die starke Persönlichkeit, die über einen Raum gebietet, der weiter als der Cosimos ist. Und sie besitzt eine intensive erotische Ausstrahlung, die den jungen Mann in ihren Bann zieht.

Die schöne Viola ist in der Liebe mittlerweile sehr erfahren und mehr noch: Sie pflegt, ihre Liebeserfahrungen ständig auszuweiten, um diese für neue Liebeskonzeptionen offenzuhalten. Da kann der an Harmonie und Ausgleich, an Natürlichkeit und Mäßigung orientierte Cosimo bei weitem nicht mithalten, tritt ihm doch nun die raffinierte und im Buch vom Erzähler Biagio als pervers deklarierte Liebeserfahrung der wollüstigen jungen Marchesa gegenüber. Viola ist nun einundzwanzig oder zweiundzwanzig Jahre alt und verführerischer denn je. Sie ist keinen Zügelungen mehr unterworfen und kann, wie sie selbst sagt, endlich tun und lassen, was ihr Spaß macht. Und der liebeslustigen Witwe macht sehr viel Spaß.

Auch an dieser Stelle folgen nun Szenen, die keinen Eingang in das Schulbuch fanden, getreu Dantes Motto „An jenem Tage lasen sie nicht weiter“: Quel giorno più non vi leggemmo avante. Doch wir wollen weiterlesen, jenseits der Grenzen einer italienischen Schulbuchausgabe. Die Liebe ist - wie auch das Schreiben - hoch in die Bäume projiziert, in jenes Gewebe an Ästen und Blättern, 
das Fragonard in seinem Gemälde so liebevoll ausmalte und das Calvino mit anderen Texten und Inhalten füllt. Im Namen des italienischen Schriftstellers erobern sich die beiden Liebenden nun diesen letzten, von ihnen zuvor noch nicht gemeinsam beherrschten Raum des Gemäldes und ihrer Sehnsüchte:

\footnotetext{
„Küss mich!“

Er drückte sie gegen den Stamm, küsste sie. Als er aufblickte, wurde er ihrer Schönheit gewahr, als hätte er sie niemals zuvor gesehen. „Mein Gott: wie schön du bist ... “

„Für dich“, und damit knöpfte sie ihre weiße Bluse auf. Ihre Brüste waren jung, mit rosa Wärzchen. Cosimo konnte sie nur eben streicheln, Viola entschlüpfte ihm über die Zweige, dass es schien, als flöge sie, er kletterte hinter ihr her und hatte ihren Rock vor Augen. [...]

Sie erkannten sich. Er erkannte sie und sich selbst, denn in Wahrheit hatte er sich noch nie gekannt. Und sie erkannte ihn und sich selbst, denn obgleich sie sich schon immer gekannt hatte, war es ihr doch noch nie vergönnt gewesen, sich auf solche Weise zu erkennen. ${ }^{7}$
}

Dies ist zweifellos der Höhepunkt des erotischen Liebesspiels auf den Bäumen. Das Äpfelchen von Viola hatte zusammen mit ihrem Füßchen und Schühchen nicht zu viel versprochen. Das paradiesische Versprechen der Eva und ihres Apfels ist eingelöst, und die Liebenden werden folglich bald schon aus ihrem Paradies vertrieben. Unsere beiden Liebenden werden bald nach dieser Szene die Grenzen des Liebesspiels erreicht haben, zu sehr sind sie in ihren gegensätzlichen Liebeskonzeptionen und Weltanschauungen gefangen. Das Paradies auf den Bäumen ist nur von kurzer Dauer; aber unauslöschlich ist der Augenblick ihrer Erkenntnis und Selbsterkenntnis in und durch die Liebe: denn er erkannte sie und dadurch sich selbst und sie erkannte ihn und dadurch sich selbst. Ihm und ihr war es noch nie vergönnt gewesen, sich auf solche Weise zu kennen. Die Ekstase wird hier nicht vorrangig als sexuelle Handlung, sondern auch als eine Vereinigung im metaphysischen Erkenntnisraum verstanden und zugleich als eine Vermengung, als ein Ineinander von Körper und Leib, von Leib-Sein und Körper-Haben, in dem sich die Liebenden so zu erleben und erfahren vermögen, wie sie sich alleine niemals hätten wahrnehmen können. Das also ist die Liebe! Die schönste Zeit des Lebens hatte für beide begonnen: Und sie lieben einander über dem Abgrund, wie es im Text heißt. Doch - um noch einmal Friedrich Nietzsches berühmten Satz zu bemühen - „alle Lust will Ewigkeit, [...] will tiefe, tiefe Ewigkeit“ ...

Das Aufeinanderprallen zweier grundsätzlich verschiedener Liebeskonzeptionen, wie sie in der Tat auch in verschiedenen philosophischen und religiösen Systemen wurzeln, kann am Ausgang des 18. Jahrhunderts, noch vor

7 Calvino, Italo: Il barone rampante. Mailand: Mondadori 1990, S. 138. 
der unmittelbar bevorstehenden Französischen Revolution, nicht gut gehen. Ersparen wir uns die Chronik eines angekündigten Abschieds: Eine Trennung der beiden ist unvermeidlich, ein happy end unserem Cosimo und seiner Viola im Gegensatz zum Liebespaar in Se una notte d'inverno un viaggiatore nicht vergönnt. Dafür ist Cosimo zum Weltdeuter und Menschenfreund, zum Weltweisen (wie man damals sagte), zum Philosophen geworden. Ein Mann der Bücher, ein Mann des Lesens, aber auch in Liebesdingen jetzt erfahren.

Die auf die endgültige Trennung der beiden Liebenden folgenden Jahre bilden eine Girlande für den Leser leicht zu rekonstruierender historischer Ereignisse, die vom Zeitpunkt der Französischen Revolution von 1789 über die Auseinandersetzungen in Italien, die Kriege der französischen Republik, dann des Kaisers Napoleon bis hin zur Neugliederung Europas unter den Gesetzen der Restauration und damit all jener restaurativen und reaktionären Ideen führen, gegen die Cosimo ein Leben lang gekämpft hatte. Nein, es war ihm nicht vergönnt, ein Staatswesen unter den Bäumen wachsen zu sehen, wie er es sich gewünscht und vorgestellt hätte.

An dieser Stelle lässt sich gewiss jene bereits erwähnte politische Lektüre des Textes durch Ulrich Schulz-Buschhaus einführen, die für den Ablauf des gesamten Romans die Entwicklung der hinter dem Erzähler sichtbar werdenden deplorablen, anti-utopischen Situation des Italiens der fünfziger Jahre von der optimistischen Allegorie zur Enttäuschung skizzierte: Jene Entwicklung, die von der Rebellion, dem Engagement, der Aufklärung, bis hin zur misslungenen Revolution und schließlich zur Restauration führt. ${ }^{8}$ So entsteht ein gewaltiges historisches Fresko.

Im letzten Kapitel haben wir das Jahr 1820 und damit zugleich das Ende der Romandiegese erreicht. Fünfzig Jahre sind seit der Schneckensuppe vergangen, die Cosimo als Zwölfjähriger vehement zurückgewiesen hatte. Wieder sind die alten Mächte an der Macht, nichts scheint sich verändert zu haben. Einen Ausweg kann auch die Liebe nicht mehr eröffnen: Sie böte bestenfalls die Chance einer Evasion.

Die Welt von Kindheit und Jugend jedenfalls sind nicht mehr. Cosimo dürfte nun etwa fünfundsechzig Jahre alt sein - und er liegt im Sterben. Man bittet ihn, auf den Boden zurückzukehren, denn klar ist, dass er ja eines Tages wieder in den Boden kommen und zu Staub zerfallen werde. Doch nicht Cosimo: Noch immer gilt sein Wort, nicht mehr von den Bäumen herabzusteigen. Ist der politische Fortschritt auch ausgeblieben, so macht sich doch der technische Fortschritt bemerkbar. Es erscheint eine Montgolfiere am Horizont, deren Seil mit Anker

8 Vgl. Schulz-Buschhaus, Ulrich: Calvinos politischer Roman vom Baron auf den Bäumen, S. 17-34. 
über die Bäume von Ombrosa streicht. Cosimo erkennt die Chance, springt auf den Anker und lässt sich von der Montgolfiere mit aufs Meer hinausnehmen. Als die Montgolfiere auf der anderen Seite der Bucht wieder landet, ist der Platz auf dem Anker leer.

So blickt auch der Erzähler Biagio am Ende dieses letzten Kapitels in einen Himmel und auf Bäume, die leer sind und leer bleiben. Und doch entwickelt sich gerade hieraus ein Romanschluss, wie er schöner wohl selten geschrieben wurde, laufen in ihm doch nochmals sämtliche Erzählfäden des Romans zusammen, um sich dann im Nichts zu verlieren. Hatte Tonio Cavilla den incipit, den Romananfang hervorgehoben, indem er darauf verwies, dass drei Grundthemen des Romans in ihm schon anklängen, so bildet der Schluss doch gleichzeitig den poetologischen Höhepunkt des Romans. Es lohnt sich also, ganz genau zu lesen:

Von Zeit zu Zeit halte ich inne im Schreiben und trete ans Fenster. Der Himmel ist leer, und uns alten Ombrosanern, die wir gewohnt waren, unter jenen grünen Kuppeln zu leben, schmerzen die Augen bei seinem Anblick. Fast scheint es, als hätten die Bäume nicht standhalten können, nachdem mein Bruder weggegangen ist, oder als wären die Menschen von der Raserei der Äxte befallen worden. [...]

Ombrosa ist nicht mehr. Wenn ich zum entvölkerten Himmel hochschaue, frage ich mich, ob es wirklich existiert hat. Diese Enklave aus Zweigen und Blättern, Gabelungen, Samenlappen und Flaum, die so winzig war und endlos, dieser Himmel, der nur aus regellosen Lichtspitzern und Fetzen bestand, vielleicht gab es das alles nur, damit mein Bruder mit seinem leichten Schwanzmeisengang darüber hinweghuschen konnte, ein Stickmuster war es, über dem Nichts gewoben, diesem Tintenfaden gleichend, den ich über Blätter und Blätter laufen ließ, beladen mit Korrekturen, Strichen, nervösen Klecksen, Flecken, Lücken, diesen Faden, der sich zuweilen zu dicken, lichten Beeren ausweitet, zuweilen sich, wie zu punktförmigen Samen, zu winzigen Zeichen verdichtet, bald in sich selbst zurückschlingt, bald sich gabelt, bald Satzklümpchen mit Blätter- oder Wolkengirlanden verbindet und dann stockt und sich abermals zu verschlingen beginnt und läuft und läuft und sich in einer letzten törichten Traube von Worten Ideen Träumen abspult und verwickelt und endet.9

Wieder ist das Buch zu Ende und mit ihm das Leben - und auch das Leben der Schrift. Der Erzähler Biagio erkennt, wie jenseits der von ihm so lange für real gehaltenen Realität eine andere Realität aufscheint und sich metaphorisch einschleicht in die andere Welt, sie gleichsam als undurchdringliches Dickicht unterwandert und schließlich in ihrer Baummetaphorik in die Text- und Gewebemetaphorik hinüberführt. Die Äste und die Zweige verwandeln sich - oder ist es umgekehrt? - in jene fortgeführte Linie des Schreibens, der Tinte, die sich ihren eigenen Weg sucht und ihr eigenes Dickicht schafft, so dass nun der Blick aus

9 Calvino, Italo: Il barone rampante 1965, S. $240 \mathrm{f}$. 
dem Fenster letztlich der Blick in die Leere ist, die Fülle doch nicht außerhalb des Textes, sondern nur in ihm zu finden ist.

Das Ende des Romangewebes ist selbstverständlich auch das Ende des Erzählers selbst, der hier zugleich mit der Autorfigur verschmilzt, nicht dem realen Autor zwar, wohl aber einer Figur, die doch unverkennbar einen höheren Abstraktionsgrad und ein höheres Reflexionsvermögen besitzt, als dies Biagio bislang vorzuführen in der Lage war. Der ricamo fatto sul nulla zeigt in aller Deutlichkeit, wie sehr der ganze Roman das Ergebnis einer bewussten Konstruktion, einer bewussten Schöpfung ist, die freilich dennoch nicht allein den Gesetzen ihres Schöpfers gehorcht. Denn sie entwickelt ihr Eigen-Leben.

Die Welt ist leer ohne den Barone rampante: Die Bäume, die Welt, die Federstriche scheinen nur für seine Bewegungen gemacht. Doch ist der Baron in das Nichts zurückgekehrt, aus dem ihn die Verzweigungen und Bifurkationen und Striche und das ganze Dickicht der Sätze geholt und zusammengesetzt hatten. Die Literatur und das Schreiben erscheinen so letztlich als der ricamo fatto sul nulla, als eben jene Kraft, die in der Lage ist, die Strickarbeit auf dem Nichts, das Weben des Textes zu bewerkstelligen. Das Ineinanderschlingen und Verweben dieser Gewebemetaphorik lässt am Ende selbst den Autor in seinem Text verschwinden. Ombrosa gibt es nicht mehr, es ist verschwunden: Und doch ist das Gewebe des Textes da, welches die Leserschaft in der Form des Buches in ihren Händen hält.

Es ist diese Mmetaphorik, die - das macht der Begriff Text selbst schon deutlich - keineswegs im 20. Jahrhundert erfunden wurde. Dort aber erhielt sie eine deutlich andere Definition und Deutung, in welcher sich die Poetik der zweiten Hälfte unseres Jahrhunderts ihre Formen der Selbstverständigung über sich und die Welt suchen sollte. Die Texttheorie, die im Verlauf der siebziger Jahre bereits zum Textualitätsdogma zu erstarren begann, die Rede von der écriture, von der Schriftlichkeit, die zunehmend die Mündlichkeit und die Oralität verdrängt und zuletzt auch noch den Autor kassierend selbst zur Produktivität werden sollte: In diesem Textschluss von Calvinos Baron, der der für real gehaltenen Realität so nah und zugleich doch so fern ist, erscheint all dies noch in einer Flüssigkeit, die jene der Tinte selbst ist, bevor diese zum Robbe-Grillet'schen miroir d'encre erstarrte. Wir könnten durchaus sagen, dass sich in dieser Passage schon der „Tod des Autors“ von Roland Barthes, die Schreibweise und die Poetik, die écriture und die trace selbst nicht nur ankündigen, sondern aufspüren und dekonstruieren, gleichsam avant la lettre oder vor der Postkarte Derridas. Die Literatur ist der Theorie immer einen schönen Schritt voraus.

So haben wir es mit einer literarischen Ausgestaltung zu tun, die den Autor zum Verschwinden bringt und sich mit jener etwas halsbrecherischen Metaphorik von Roland Barthes verknüpfen lässt, die den Autor sich im Spinnennetz seines Gewebes selbst auflösen sieht. Mithin macht Biagio dem ricamo fatto sul 


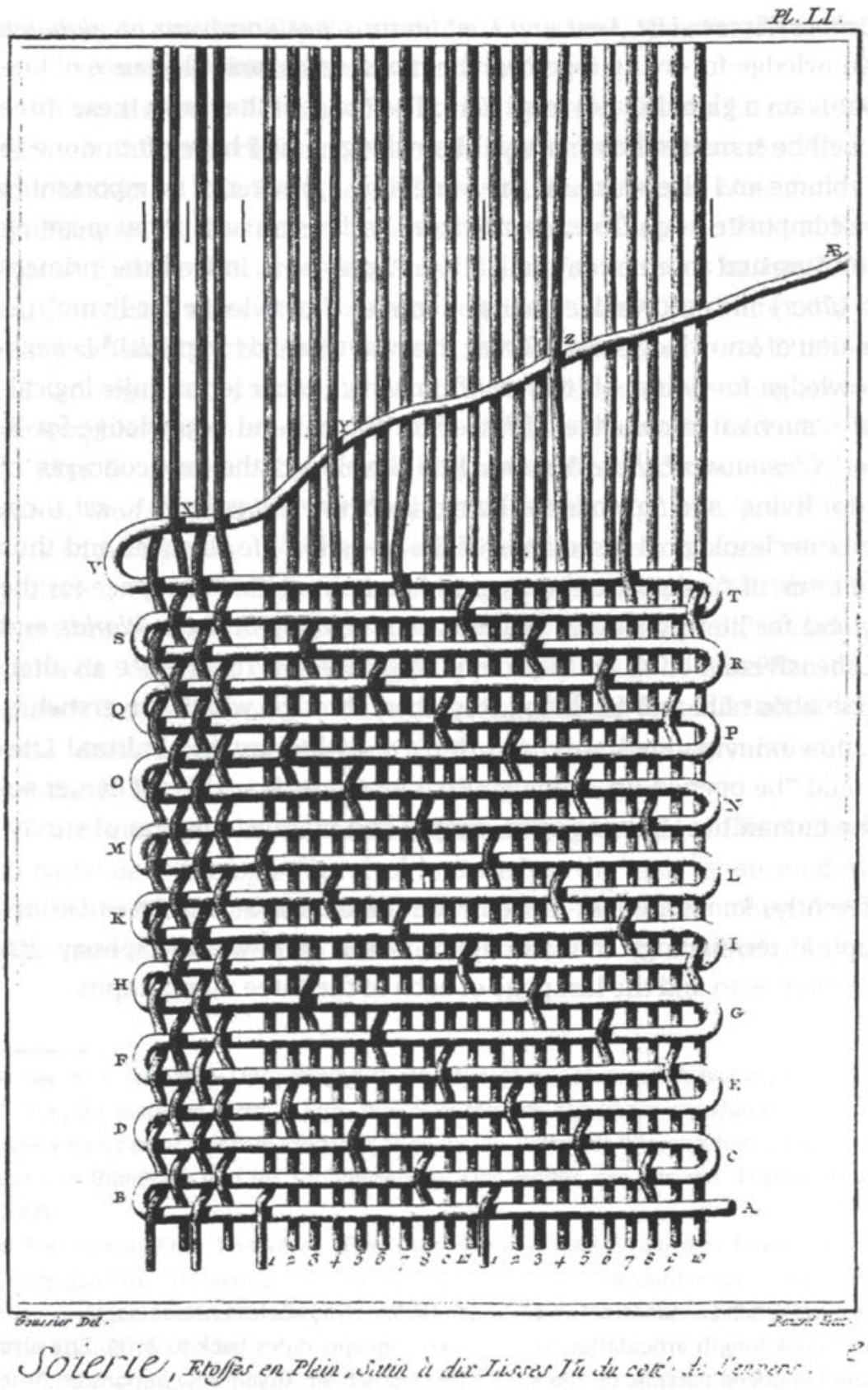

Abb. 40: Der Text als Gewebe, „Soierie. Etoffes en plein. Satin à dix Lisses. Vu de côté de l'envers.“, Kupferstichtafel aus der Encyclopédie von Denis Diderot et Jean le Rond d'Alembert. 
nulla Platz, einem Gewebe, das sich zunehmend seiner eigenen Produktivität als Text bewusst wird.

Doch ist - wie wir schon sahen - nicht nur das Textgewebe produktiv, sondern auch die Leserschaft und insbesondere das Lesen selbst. Mit den Worten von Barthes wird der Tod des Autors mit der Geburt des Lesers bezahlt. Doch wollen wir an dieser Stelle nicht die großen Theoriedebatten der sechziger und siebziger Jahre in Frankreich aufrollen. Unser tour d'horizon verschiedener Leserfiguren und Lesemodalitäten geht hier zu Ende und macht schon bald einer stärker chronologisch ausgerichteten Betrachtung Platz, die wir - und Calvinos Baron war ein Schritt hierzu - im 18. Jahrhundert beginnen lassen. Bevor wir damit anfangen, möchte ich Ihnen ein kurzes Zitat von Alberto Manguel zur Macht des Lesens und zur Macht der Leserinnen und Leser nicht vorenthalten. Denn dies schrieb der argentinische Diplomatensohn nicht nur vor dem Hintergrund der argentinischen Militärdiktatur:

\begin{abstract}
Nicht nur totalitäre Regime fürchten das Lesen. Auch auf Schulhöfen, in Umkleideräumen, in Regierungsämtern und Gefängnissen wird die Gemeinde der Leser mit Mißtrauen betrachtet, weil man ihre Autorität und potentielle Macht spürt. Die Beziehung zwischen Buch und Leser wird zwar als nützlich und fruchtbringend anerkannt, gleichzeitig aber gilt sie als hochmütig und abweisend, vielleicht weil der Anblick eines Lesers, der sich in die Ecke zurückgezogen und die Welt und sich vergessen hat, auf eine undurchdringliche Privatsphäre hinweist, einen selbstbezogenen Blick und einsames, eigensüchtiges Handeln. („Geh raus und lebe“, sagte meine Mutter immer, wenn sie mich lesend fand, als hätte meine stille Beschäftigung ihrer Vorstellung vom Leben widersprochen.) [...]

Borges erzählte mir einmal von den populistischen Demonstrationen, die die PerónRegierung 1950 gegen opponierende Intellektuelle organisiert hatte und auf denen die Demonstranten skandierten: „Schuhe ja, Bücher nein!“ Die Replik „Schuhe ja, Bücher auch!“ überzeugte niemanden. Die Wirklichkeit, die harte, nüchterne Wirklichkeit, wurde als unvereinbar mit der flüchtigen Traumwelt der Bücher empfunden. Unter diesem Vorwand wird der künstliche Gegensatz zwischen Lesen und Leben von den Mächtigen erfolgreich geschürt. Populistische Regierungen verlangen, daß wir vergessen, und deshalb brandmarken sie Bücher als überflüssigen Luxus; totalitäre Regime verlangen, daß wir nicht denken, und darum verbieten, verfolgen und zensieren sie den Geist; beide wollen uns dumm und unterwürfig machen im großen und ganzen und begünstigen daher den Konsum von TV-Müll. Unter solchen Umständen können Leser gar nichts anderes sein als subversiv..$^{10}$
\end{abstract}

Wir wollen der Subversivität des Lesens als Thema im Umfeld der von uns zu verfolgenden Lektüreprozesse weiter nachgehen. Zugleich aber wollen wir darüber nicht vergessen, dass nicht nur das Lesen, sondern auch die Liebe eine hochgradig gesellschaftsverändernde Kraft besitzt, die freilich immer wieder auf die

10 Manguel, Alberto: Eine Geschichte des Lesens, S. 32. 
Probe gestellt und gesellschaftlich herausgefordert wird. Wie prägend Liebeskonzeptionen für Aufbau und Struktur ganzer kultureller Formationen - wie etwa jener des Abendlandes - sind oder sein können, wurde in einer heute als klassisch zu bezeichnenden Studie untersucht, die wir uns zum Abschluss dieses ersten Hauptstückes unserer Vorlesung vornehmen wollen. 